\title{
Performance analysis of electricity generation by the medium temperature geothermal resources: Velika Ciglena case study
}

\author{
Predrag Raškovića, ${ }^{a}$, Zvonimir Guzović ${ }^{b}$, Svetislav Cvetković ${ }^{a}$ \\ ${ }^{a}$ Faculty of Technology, University of Niš, Bulevar Oslobođenja 124, 16000 Leskovac, Serbia \\ ${ }^{\mathrm{b}}$ Faculty of Mechanical Engineering and Naval Architecture, University of Zagreb, Ivana Lučića 5, 10002 Zagreb, p.p. 102, Croatia
}

\section{A R T I C L E I N F O}

\section{Article history:}

Received 19 December 2011

Received in revised form

22 February 2013

Accepted 2 March 2013

Available online 6 April 2013

\section{Keywords:}

Geothermal energy

Velika Ciglena in Croatia

Binary cycles

Equation-oriented simulation

Performance analysis

\begin{abstract}
A B S T R A C T
During the last decade, a design of an energy efficient and cost effective geothermal plant represents a significant and on-going technical challenge in all the Western Balkan countries. In the Republic of Croatia, the geothermal field Velika Ciglena is identified as one of the most valuable geothermal heat sources and probably the location where the first geothermal plant in the Western Balkan area will be built. The purpose of this work is the conceptual design and performance analysis of the binary plants -the one which operates under the Organic Rankine Cycle (ORC) and the other under Kalina (KLN) cycle-which can be used for geothermal energy utilization in Velika Ciglena. A conceptual plant design is performed by the equation-oriented modelling approach and supported by the two steady-state spreadsheet simulators. The performance analysis of all design solutions is conducted through energy and exergy analysis, and by the estimated total cost of operating units in the plant. The results of the analysis indicate that the plant design based on the ORC cycle has a higher thermodynamic efficiency and lower cost of equipment, and consequently, it is more suitable for the future geothermal plant in Velika Ciglena.
\end{abstract}

(c) 2013 Elsevier Ltd. All rights reserved.

\section{Introduction}

During the last century, geothermal energy [1-3] has been commonly used for commercial, industrial, and residential direct heating purposes ("direct use"), for electricity production, and for efficient home heating and cooling through geothermal heat pumps. Its use primarily depends not only on geothermal resource quality, quantity and projected production, but also on specific technological and economic criteria. In 2008, geothermal energy was utilized "directly" in 78 countries, generating $121.7 \mathrm{TWh} / \mathrm{yr}$ (0.44 EJ/yr) of thermal energy [4], while electricity production was actualized in only 24 countries, with an estimated production of $67.2 \mathrm{TWh} / \mathrm{yr}(0.24 \mathrm{EJ} / \mathrm{yr})$. Today, only $0.3 \%$ of the world's electricity is generated from geothermal sources (International Geothermal Association) but, in the future, geothermal power production is expected to steadily increase, reaching a share of $0.6 \%$ by the year $2030[5,6]$.

In the West Balkan Countries (http://www.westbalkanresearch. net/), specifically in the Republic of Croatia, the use of geothermal

\footnotetext{
* Corresponding author.

E-mail addresses: pr.raskovic@sezampro.rs (P. Rašković), zvonimir.guzovic@ fsb.hr (Z. Guzović), sveta983@hotmail.rs (S. Cvetković).
}

energy is limited only to direct use, usually for medical purposes. In order to promote geothermal activities, especially electricity production from geothermal sources, the scientific institutions and public companies in Croatia started a comprehensive geological and geophysical research in the early 1970s [7-9]. In the late 90s, the Energy Institute "Hrvoje Požar" prepared a comprehensive survey [10], which signified the five locations with the highest geothermal potential for electricity production. Among them, the geothermal field Velika Ciglena, situated $11 \mathrm{~km}$ southeast from the city of Bjelovar, was identified as the most promising location for the construction of the first geothermal power plant in Croatia.

Since that time, a few important documents have analysed the implementation of different technologies for the design and construction of a geothermal plant in Velika Ciglena. In 2010, Guzović et al. [11], presented the detailed descriptions and specifications of Velika Ciglena geothermal field, emphasising high geothermal gradients (in the range of $0.063-0.065{ }^{\circ} \mathrm{C} / \mathrm{m}$ ), and plentiful production of hot geothermal water, $\left(83.3 \mathrm{l} / \mathrm{s}\right.$, temperature $175^{\circ} \mathrm{C}$ ) of that source. In that paper, the authors also proposed two conceptual models for the future geothermal plant in Velika Ciglena. Both models were binary cycle based; the first one was operated under the Organic Rankine Cycle (ORC) and the second was operated under Kalina (KLN) cycle. In addition, the authors made a thermodynamic analysis of those plants, and the final results of their 
study opposed the widespread opinion in technical literature which claims efficiency advantages for Kalina over ORC cycle.

The research presented in this paper is a continuation and improvement of the study in Ref. [11]. The parameters of geothermal resource, ambient conditions and main parts of modelbuilding process have been adopted from that study, but the research methodology has been improved with respect to the new computer-aided design tools and more detailed performance analysis.

The paper starts with a brief presentation of the exergy analysis in the Section 2. This Section summarizes the exergy concept, its historical development and the most important terms and definitions. A short review of the scientific literature where exergy analysis is applied for the design and analysis of geothermal power plants is also presented.

The rest of the paper is illustrated in the research flowchart in Fig. 1. The flowchart delineates the research phases and procedures which are used for the design and analysis of both binary plants (ORC and KLN), with the designation that the presented route is used for each plant separately.

The physical model of the plants (ORC and KLN), modelling assumptions, and mathematical models of individual operating units are presented in the Section 3 . The section 4 considers the most important characteristic of a software tool which is used in the plant design and analysis. This part of the paper considers an equation-oriented solving strategy, mathematical consistency of numerical models (degree of freedom - DOF analysis), model

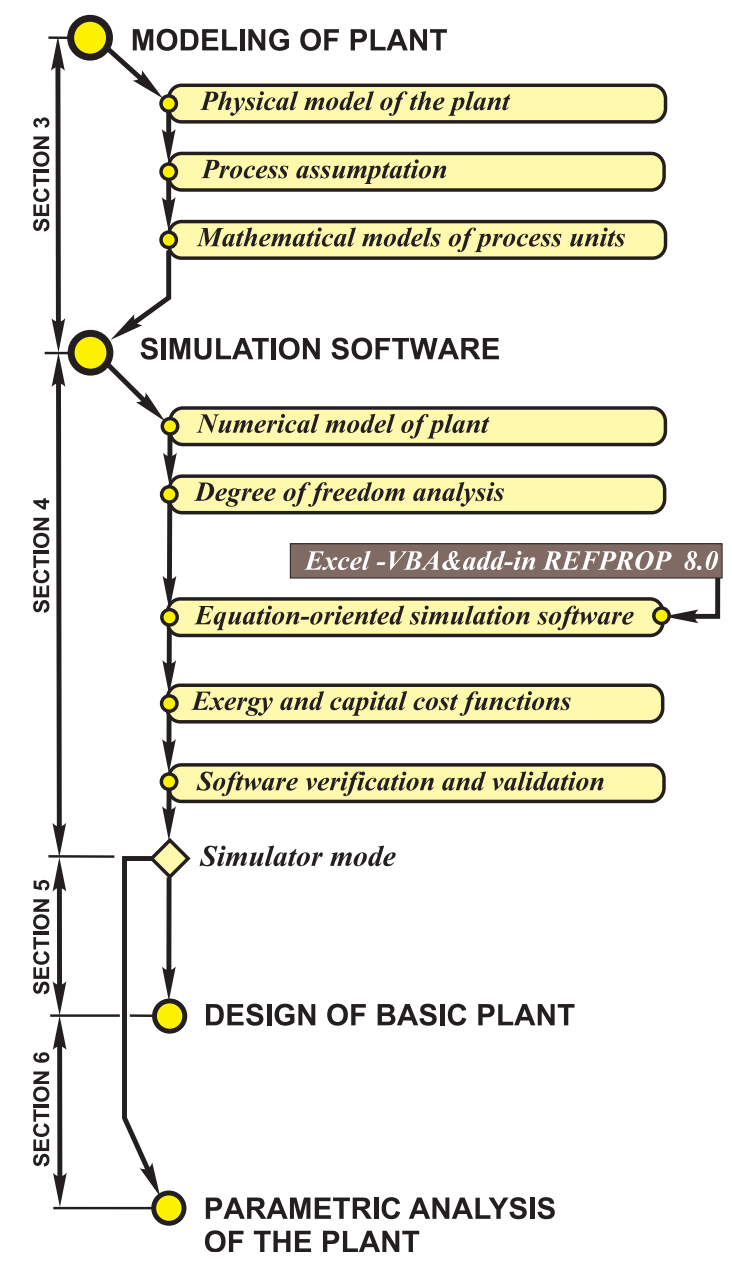

Fig. 1. Research flowchart of study presented in the paper. implementation in software codes and software validation and verification. The final part of the section explains the structure of two different software modes: design and parametric, which are employed in the design and performance analysis of the plant.

The computer-aided design and analysis of base-case plants are presented in the Section 5. The term "base-case" here denotes the plant in which operating parameters are determined by the simulation software in a design mode and under the same operating conditions as in the [11]. The results of the thermodynamic and economic analysis of both base-case plants lead to an adequate decision relating to the type of binary plant, ORC or KLN, which might be more appropriate for the application in the existing geothermal location. In the same section, the design mode of a simulator is employed to investigate the possibilities for the use of different working fluids in the ORC base-case plant.

The results of the simulations obtained by a parametric mode of software are utilized for the parametric analysis of plants in the Section 6 . The parametric studies have been performed to find out the effects of various operating parameters on the plant performances and cost. Finally, some specific tangential and very detailed elements of the study are presented in the appendix of the paper.

To prevent the linguistic confusion, e.g. to distinguish the elements used in the present study from those used in Refs. [11], in the rest of the text, the latter is referred to as "reference elements", e.g. reference cycle, reference plant, reference model, reference parameters, etc. Also, the term basic cycle (or only the cycle), in the content of the plant layout, is used to indicate the part of the plant which operates in closed binary cycle; from the physical point of view, the cycle assembles only the operating units which are in contact with the working fluid, while the plant, beside the cycle, involves additional power related units like a down-hole pump or fan.

\section{Exergy analysis-theoretical background and short literature review}

Exergy analysis is a system oriented method which combines the use of the first and the second law of thermodynamics for analysis, evaluation, development and the design of energy system. Thus, exergy analysis is considered to be an engineering analysis tool inside the wider methodology framework of the exergy concept [12]. The main purpose of an exergy analysis is to detect and evaluate causes of thermodynamic imperfection quantitatively, and to provide the guidance for a better process design. The key variables resulting from the exergy analysis like exergy destruction, exergy loss, exergetic efficiency, exergy destruction ratio etc. are well documented in numerous papers and books [13-16].

The exergy concept was originally derived by Gibbs [17] as a special case of Gibbs's available energy, while the first publications related to the exergy analysis were done by Gouy and Stodola [18]. The early stage of modern exergy analysis was initiated in the work of Bošnjaković [19] in 1938; followed by Keenan, who introduced the term "available energy" in 1948; and it was completed in the work of Rant [20], who coined the term exergy to denote "technical working capacity" in 1956. Today, there are several definitions of exergy in the open literature. All of them encompass the same basic idea but vary in the way of deriving [21]; some authors defined exergy-based on the work [22-24], the others via the reverse process [25] and some concerning the useful work [26]. From the authors' point of view, the definition provided by Tsatsaronis [27] should be denoted as the most suitable one for engineering application. Exergy is presented as the state function of system intensive variables and gradients which arise from the differences between the extensive variables of a system and environment; thereto the environment is a large, zero exergy, equilibrium system in which 
extensive variables remain constant during interactions with a thermodynamic system. In this way, exergy can be referred to not only as the universal physical measure, because all thermodynamic systems can be compared based on their exergy content, but also as the non conserved physical measure since its function is derived from the second law of thermodynamics [29].

During the last forty years, the utility of the exergy concept has gone far beyond the thermodynamic analysis of industrial and energy plants; exergy has been applied to complete the chains in natural processes for specific analysis in national economies and to assess the environmental impact of production plants. In addition, many methods which combine exergy analysis with economics in literature are referred to under different names like: thermoeconomics, second law costing, exergoeconomics, exergy economy accounting, and exergy economy optimization [30-36].

According to the literature review, in the field of geothermal energy, the exergy concept is commonly related to the problems of classification/evaluation of resources [37-45] and to the problems of design and analysis of geothermal facilities. In the second case, the exergy analysis is usually associated to open steady-state systems and control volume (CV) applications.

Historically, exergy analysis of a geothermal power plant was first introduced in 1972 by Bodvarrson and Eggers [46] who compared the performances of a binary plant based on the single and double flash cycles. Later, in 1978, Brook, Mariner, Makey, Swanson, Guffanti and Muffler [47] applied the exergy concept for geothermal system analysis, and in the same year Kestin [48] presented theoretical consideration about the available work and its use in a geothermal plant. In 1984, DiPippo and Marcille [49] showed the advantage of efficiency calculations which are based on the Second Law of thermodynamics and the concept of exergy. In paper [50], DiPippo provided a response to the articles which proclaimed dramatic efficiency advantages for Kalina cycles over ORCs [51-53], demonstrating that in the simulation with identical conditions of ambient temperature and cooling systems, the calculated difference in performance was only about $3 \%$ in favour of a Kalina cycle. DiPippo also pointed out that ORC geothermal technology is mature, whereas the Húsavík plant was (and is today) the only commercial Kalina cycle in operation so far. In the same paper, the author calculated the overall plant efficiency (The First Law thermal efficiency and the Second Law efficiency) for a few geothermal binary power plants on different locations and with different production cycles. In 2003, Cerci [54] presented the performance of an 11.4 MW single-flash geothermal power plant in Denizli, Turkey, and used the actual plant operation data for comprehensive exergy analysis. The results of the analysis revealed that the largest exergy destruction occurs from brine discharges causing a relatively small second law efficiency of the plant. For that reason, he proposed a double flash design as the best choice to improve the plant efficiency. Thermodynamic evaluation and improvements, based on the exergy concept of the same geothermal power plant are presented in Refs. [55-57]. Koroneos at al. [58] used exergy analysis to evaluate the operation of a cogeneration geothermal plant which could be built in Eratino, Greece. They also examined the environmental impacts of that plant. Kanoglu [59] performed exergy analysis on the Stillwater binary geothermal power plant located in Northern Nevada, USA. Exergetic efficiency of all the above mentioned plants and some other [60] are summarized in Ref. [41].

Recently Ganjehsarabi, Gungor and Dincer [61] presented an exergy analysis of the Dora II (9.5 MW net power) geothermal power plant, located in Aydin, Turkey. In the case of Olkaria I Power Plant in Kenya, Kwambai [62] calculated the overall second law efficiency of a plant and presented the diagram of exergy flow through the system.

\section{Physical and mathematical models of binary plants}

The computer-aided design of geothermal plants, suitable for the generation of electricity in the field of Velika Ciglena, began with a model-building process. The model-building process is introduced as the top research stage in the flowchart in Fig. 1 to address the three coherent subtasks: drawing plant's physical models, considering and adopting model assumptions and developing the mathematical expressions which capture and describe the essential behaviour of operating units in the plants.

As it has already been mentioned, in this research stage, most of the modelling solutions are obtained using the experience and recommendations from Ref. [11], where the authors employed the technology based on binary cycles (ORC and KLN) to utilize the available geothermal potential from the same field. In order to avoid repetitions, a model-building process is presented in this paper in the way which provides a minimal overview of a complete plant design. The research elements which originate from the reference plant are only mentioned here, supposing that the reader can find more information about them in Ref. [11]. More detailed descriptions are applied only to the issues which make the distinction between the present study and the one made before.

The physical models of both plants are presented in the plant flow diagrams (PFD), Figs. 2 and 3. The basic cycles, e.g. their configurations, a type and number of operating units as well as other important information like isentropic efficiencies of pumps and turbines, minimum allowable temperature difference in heat exchange units (evaporators and heat exchangers), etc., have been taken over from the reference plants.

However, the research in the present study has slightly been modified by including two new operating units in both plants: a high pressure, down-hole, pump (HPP) in the incoming stream of geothermal water and an electric fan (FN) inside the air cooling system. The inclusion of the first element, HPP, ensured a constant mass flow rate of geothermal water in plants and prevented degassing and precipitation within pipelines. Consequently, mathematical models are built in such a way that both plants operate under steady conditions and with neglected pressure and temperature drops in a piping system. The second element, FN is primarily added

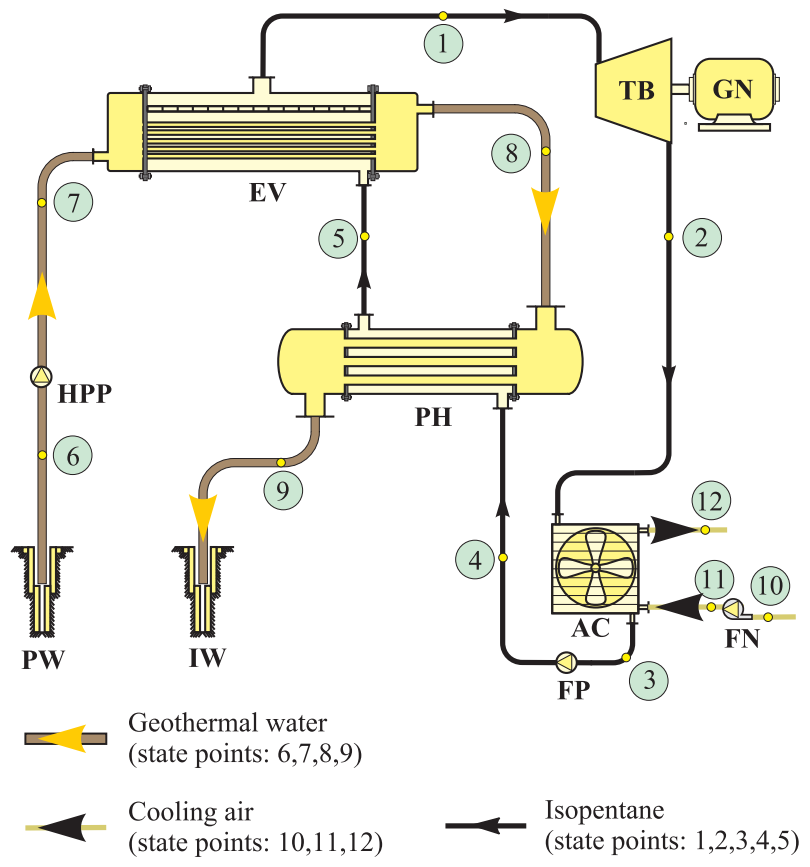

Fig. 2. Physical model of ORC plant 


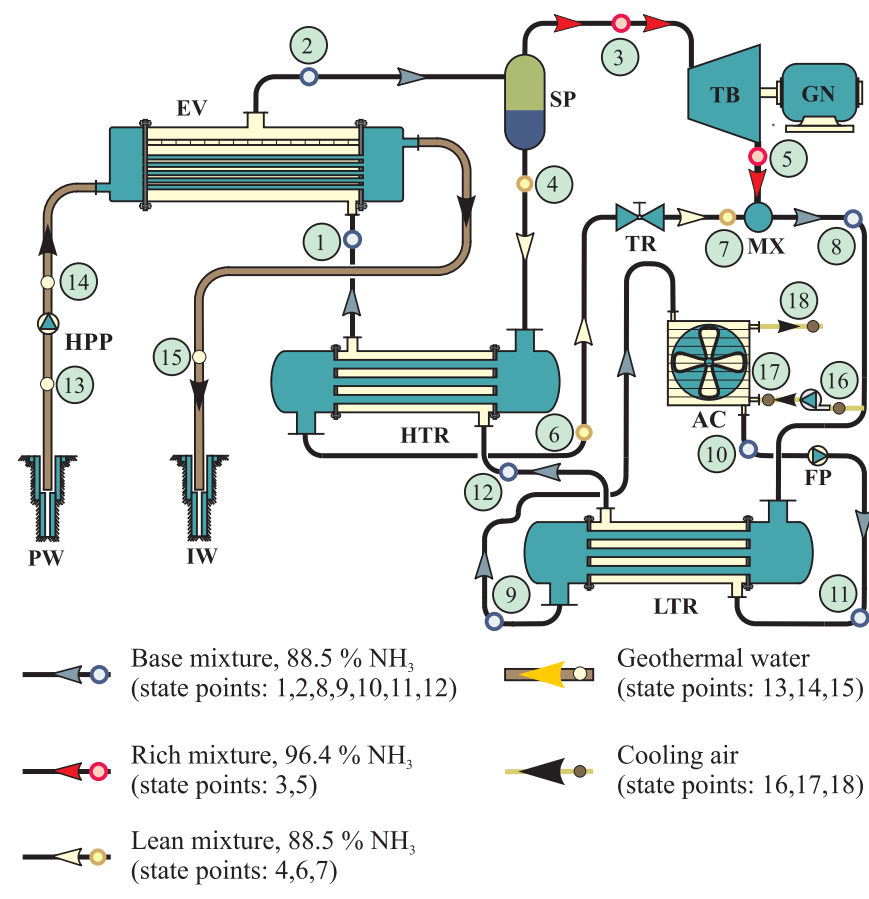

Fig. 3. Physical model of KLN plant.

to complete the material and energy balance of a cooling system, assuming that the fan produces a sufficient airflow and heat transfer over a reasonably sized Air Cooled Condenser (AC).

Based on the physical model and adopted assumptions, the mathematical models of operating units are developed by the control volume (CV) applications for open steady-state thermodynamic systems and by using the mass (1) and energy balance equations. Before that, PFD drawings are transformed in block flow diagrams (BFD), Fig. 4a and b, where the drawings of process units are replaced by rectangles which frame the desired control volumes. Block flow diagrams enable an easier input/output analysis of the CV-s, recognition of the state points in a plant and decomposition of a plant layout.

Mathematical models are developed by neglecting changes in kinetic and potential energy of streams and by assuming adiabatic processes in all CV-s. Energy balance equations are presented in the form of enthalpy balance equation (2) and then, in respect to the type of process inside the unit, they are classified in two groups: for heat exchange units (3) and for power related units (4). In the case of power related units, the element of shaft power $W_{i}$ includes the variables of isentropic efficiency (5) and thus, mathematical models of these units are described by additional entropy balance equation for adiabatic, steady-state process (6).

$\sum_{j \in \operatorname{IN}(i)} \dot{m}_{j, \text { in }}-\sum_{j \in \mathrm{OUT}(i)} \dot{m}_{j, \text { out }}=0$

- for $j=\mathrm{EV}, \mathrm{PH}, \mathrm{HTR}, \mathrm{LTR}, \mathrm{AC}, \mathrm{SP}, \mathrm{TR}, \mathrm{MX}, \mathrm{AC}, \mathrm{TB}, \mathrm{HPP}, \mathrm{FP}, \mathrm{FN}$; $i \in\{\mathrm{ORC}, \mathrm{KLN}\}$.

$\sum_{j \in \mathrm{IN}(i)} \dot{m}_{j, \text { in }} h_{j, \text { in }}-\sum_{j \in \mathrm{OUT}(i)} \dot{m}_{j, \text { out }} h_{j, \text { out }}-\dot{W}_{i}+\dot{Q}_{i}=0$

where:

- for $j=\mathrm{EV}, \mathrm{PH}, \mathrm{HTR}, \mathrm{LTR}, \mathrm{AC}, \mathrm{SP}, \mathrm{TR}, \mathrm{MX}, \mathrm{AC}$; $i \in\{\mathrm{ORC}, \mathrm{KLN}\}$. $\sum_{j \in \mathrm{IN}(i)} \dot{m}_{j, \text { in }} h_{j, \text { in }}-\sum_{j \in \mathrm{OUT}(i)} \dot{m}_{j, \text { out }} h_{j, \text { out }}=0$

- for $j=\mathrm{TB}, \mathrm{HPP}, \mathrm{FP}, \mathrm{FN}$;

$i \in\{\mathrm{ORC}, \mathrm{KLN}\}$.

$\sum_{j \in \mathrm{IN}(i)} \dot{m}_{j, \text { in }} h_{j, \text { in }}-\sum_{j \in \mathrm{OUT}(i)} \dot{m}_{j, \text { out }} h_{j, \text { out }} \pm W_{i}=0$

$h_{j, \text { in }, s(\text { in })}-h_{j, \text { out }, s(\text { out })} \pm \eta_{\text {is }}\left(h_{j, \text { IN }, s(\mathrm{IN})}-h_{j, \text { out }, s(\mathrm{IN})}\right)=0$,

$\dot{m}_{j, \text { in }} s_{j, \text { IN }}-\dot{m}_{j, \text { out }} s_{j, \text { out }} \pm \dot{S}_{g e n}=0$

As can be seen from (1) to (6), the variables in the balance equations are the mass flow rates and intensive thermodynamic properties of the substance which enter or leave the CV. The relations between thermodynamic properties create an additional constraint on thermodynamic system behaviour. This means that if the state of the system is assigned by two primitive thermodynamic propertiespressure and temperature (which is the common case in a plant design), any of its other thermodynamic properties in that state, including the derived ones-specific enthalpy and specific entropy, can be calculated with an appropriate equation of the state (EOS) [63]. This conclusion is also valid for other combinations of properties (for example, if the state is fixed by temperature and specific enthalpy, other properties like pressure, specific entropy, density, specific heat can be calculated). At the same time, the substance which constitutes the stream (pure fluid or mixture of pure fluids) has to be defined too, since the relations between state properties strongly depend on the substance type and its composition in the stream.

In a computer-aided design technique, property calculations are usually performed by one of the external Thermodynamic Property Packages. In the present study, this package is NIST REFPROP v8.0 [64], the Fortran-based program which includes state equations for a wide variety of pure fluids and mixtures. In the current spreadsheet software, the REFPROP is linked to the Microsoft Excel ${ }^{\circledR}$ using a dll statement, which enables property calculations in the same way as any other library functions.

Finally, as a part of a modelling process, plant systems are decomposed in three interrelated subsystems according to energy conversation technologies and processes within them, Fig. $3 c$ and d. The first subsystem-A is a heat exchange subsystem which incorporates the heat exchange operations between the geothermal water and working fluids. In a KLN plant, this subsystem also involves the processes of separation, mixing and throttling. The second subsystem-B is an energy conservation subsystem, while the third subsystem-C is a heat removal subsystem. There are two reasons for such mapping of the plants. First, the subsystems accomplish the same technological operations in both plants and consequently their thermodynamic performances are more comparable than the performances of single process units. This is very obvious in the case of the subsystem $\mathbf{A}$ due to the differences in the number and types of process units in ORC and KLN plants. The second reason relates to the software validation where subsystems $\mathbf{A}$ and $\mathbf{C}$ are treated as disjoint systems of the equations [65] that can be solved independently. The solutions from the disjoint systems are used as control values of the overall simulation process.

\section{Simulation software}

The main difference between the present study and [11] began in the second research phase where the numerical models and 


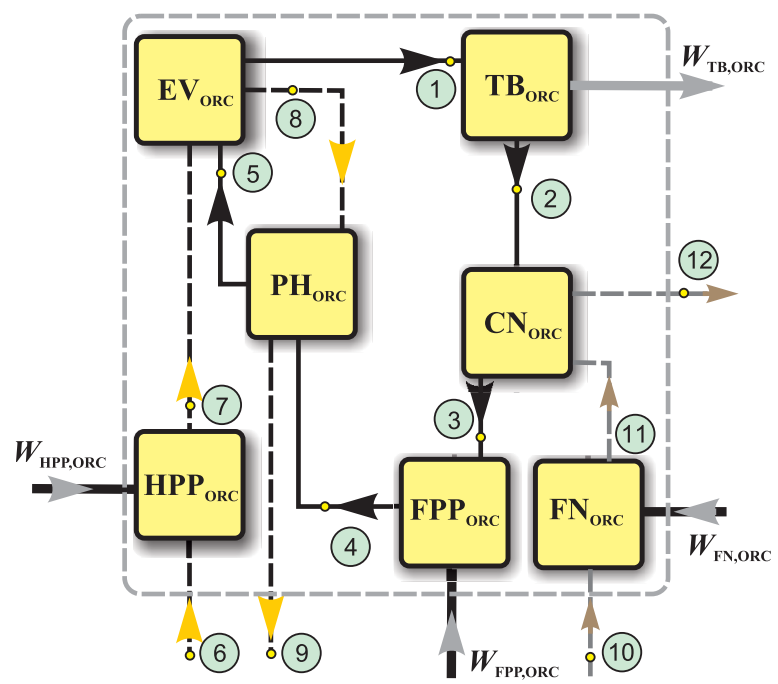

a)

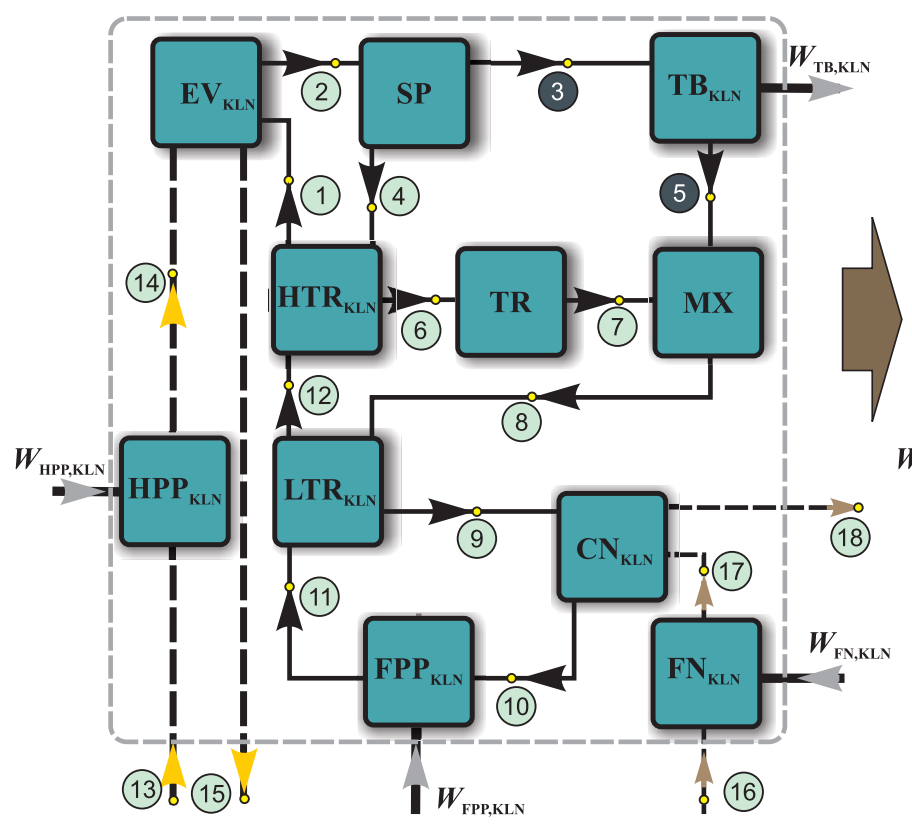

b)

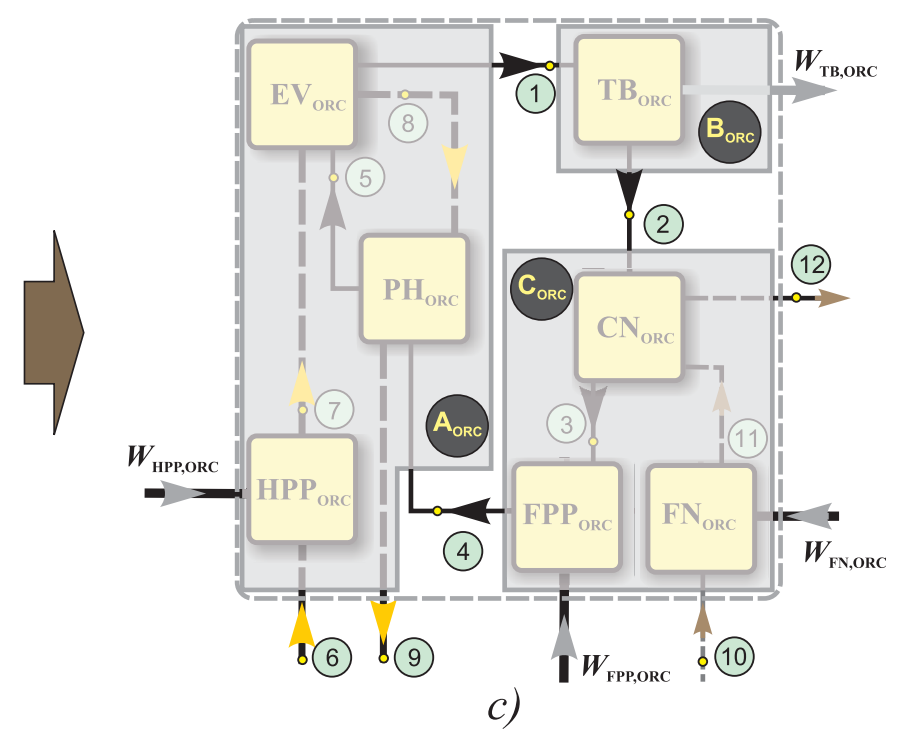

c)

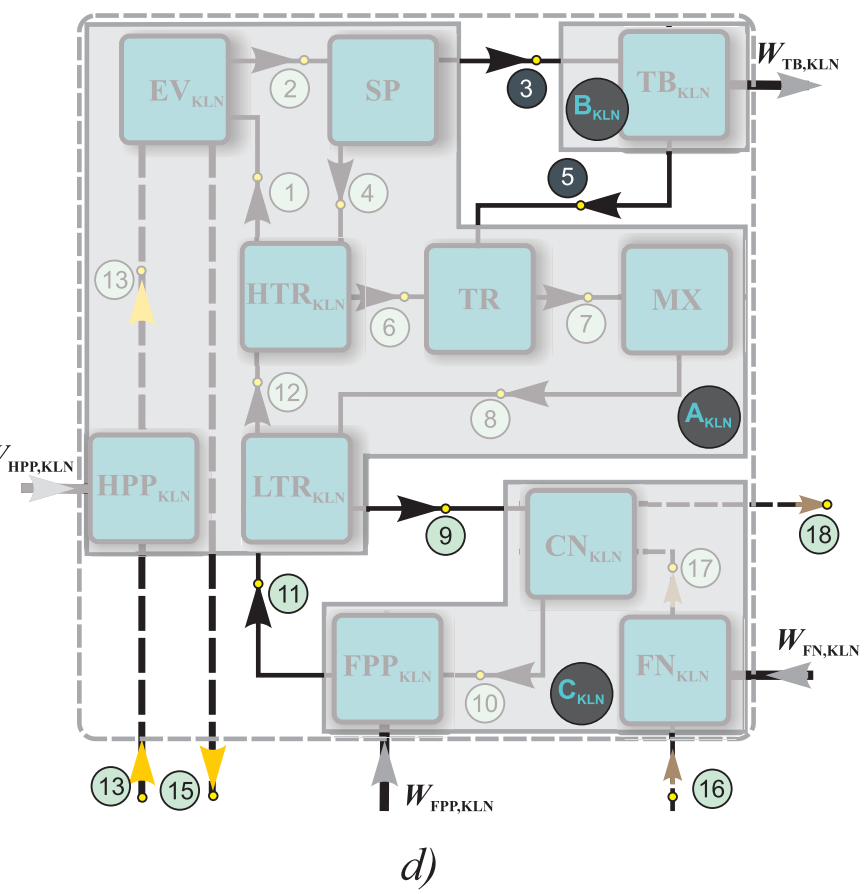

d)

Fig. 4. Block flow diagrams of ORC and KLN plants.

associated procedures diverted the investigation to the new kind of a computer-aided design technique. The sequential modular strategy used in Ref. [11] enabled a single design and analysis of the base-case plants, but it also limited the research space. It became obvious that additional analysis and possible improvements of a plant performance cannot be achieved without the use of specialized software tools.

For that reason, in the new study, the process of a plant design and analysis was supported by the two steady-state spreadsheet simulators associated to the physical and mathematical models of ORC and KLN plants. Since the simulators have the same structure and operating procedure, the explanation in the rest of the text will be directed only to one of them.

A plant simulator deals with a specification (design) problem [66], where instead of all input information, some input and some output or intermediate information determine the remaining input and output information. Thus, input and output information are operating conditions and equipment parameters/sizes while, intermediate information is related to the minimum temperature difference of streams in heat exchange process units. Due to the nature of the problem, the authors decided to use the equationoriented solution strategy (EO) [67] for software development.

Following the rules of EO strategy, the equations which are obtained by a model-building process are first assembled together into a numerical model of a plant, and then examined by DOF analysis $[68,69]$. The degree of freedom analysis determines a "so called" number of DOF, e.g. the number of variables, which must be specified in advance to ensure that the number of the remaining variables equals (since the task is a simulation, not optimization) the number of the independent equations. The former variables are declared as the "independent or design variables" while the latter are the "unknown variables". 
The key issue of DOF analysis is the exact number of independent and unknown variables. Before its conversation in a software code, the numerical model of a plant has to include only the above mentioned information, while the declaration of variables is a part of a software procedure. It should be also noted that in an equationoriented simulation, a solving process is feasible only when all variables are specified. After that, independent variables become constants in equations, while the values of unknown variables change and progressively approach the final solution during the iteration procedure. As a consequence, the input of unknown variables has to be estimated in the way which minimizes the difference between their assigned values and its values in the final solutions.

The degree of freedom analysis for the base-case plants is illustrated in the Appendix, Table A1. The numbers in the last row of the table signify 16 independent variables in ORC plant and 20 in KLN plant which have to be specified in advance to ensure a mathematical consistency of their numerical models.

After DOF analysis, the numerical model of a plant is translated in the software code of a simulator. The software code was developed by the VBA Integrated Development Environment of Microsoft Excel ${ }^{\circledR}$ and supported by the REFPROP property package. The plant simulator consists of three interconnected functional parts which are presented by the flowchart in Fig. 5a.

The operating procedure in the Input part includes the declaration of variables and the input of their initial value. It was mentioned earlier that the DOF analysis determines only the mandatory numbers variables, but does not declare which variable is independent or unknown. For that reason, by default, the variables are declared for the base-case plants (see Section 5 and Appendix 1 Fig. A1). During the research, the default declaration is sometimes modified in the way that the variable which has been declared as an unknown one in the base-case plant is converted in the independent variable and vice versa. To prevent the break of consistency in numerical model, the change of the declaration of an unknown variable is always followed by the same acting on independent variable (free choice of operator), but in the opposite direction. Here, the direction is related to the type of variable, e.g. independent or unknown.

The solver part of the program includes the procedure for solving the set of nonlinear equations defined by numerical models of the plant. In the first step of iteration, the dynamic-link library which acts as an interface starts, making it possible for Excel to access properties from REFPROP data-base through code enquiry. After that, the solving process employs the Excel Solver add-in tool for iterative procedure which generates successive approximations of unknown variables to the final solutions. When the process is completed, the solutions, thermodynamic properties of all streams and process quantities related to the power and heat duty $\left(\dot{W}_{\mathrm{TB}}, \dot{W}_{\mathrm{FP}}, \dot{W}_{\mathrm{HPP}}, \dot{W}_{\mathrm{FN}}, \dot{Q}_{\mathrm{EV}}, \dot{Q}_{\mathrm{AC}}, \dot{Q}_{\mathrm{PH}}, \dot{Q}_{\mathrm{LTR}}, \dot{Q}_{\mathrm{HTR}}\right)$ are transferred in the output part of the simulator for additional processing.

The output part of a simulator includes an independent subroutine which calculates thermodynamic and economic performances of the plant and its components (operating units and subsystems). The thermodynamic performance of the plant is obtained by the energy and exergy analysis of the plant, while the economic performance of the plant is calculated as the total cost of equipment (only operating units) in the plant. Next paragraphs describe these expressions by stating only the performance which is presented in the current paper.

The energy based performances deal with energy conversion quantities of the cycle and the plant. The former quantity is referred to energy efficiency of geothermal cycles, $\eta_{\mathrm{th}, \mathrm{c}}$, while the latter is referred to energy efficiency of the plant $\eta_{\text {th,p }}$ [70]. Inside the subroutine, these preferences are calculated by the following expression:

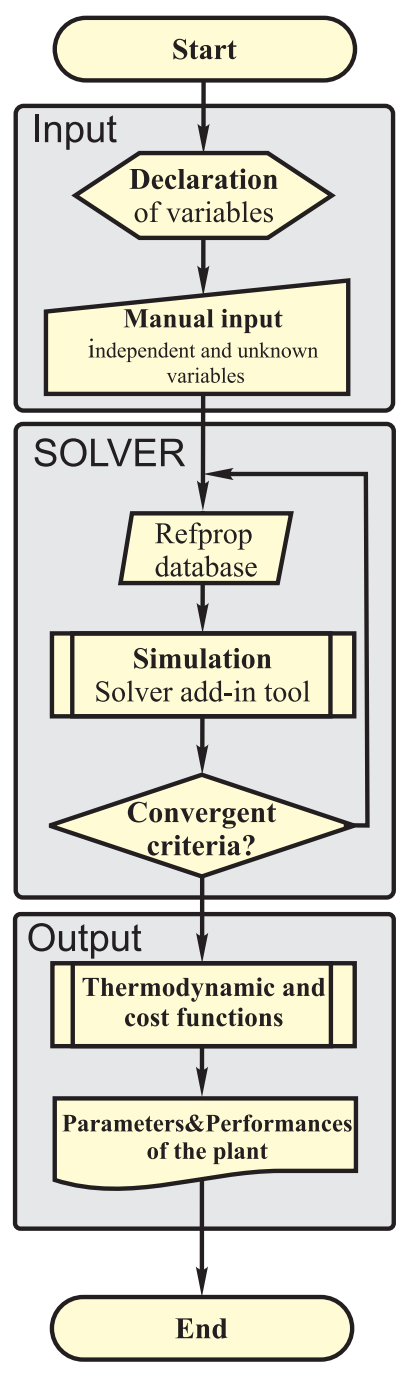

a)

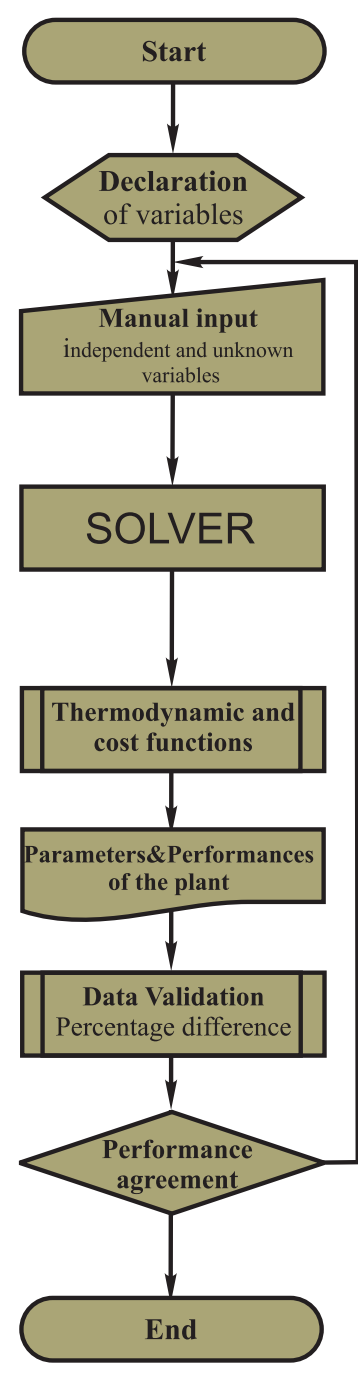

b)
Fig. 5. Software flowcharts a) simulator structure b) algorithm of V\&V procedure.

$\eta_{\mathrm{th}, \mathrm{K}}=\frac{\dot{W}_{\mathrm{NET}, \mathrm{K}}}{\dot{\mathrm{Q}}_{\mathrm{in}}}$

where are :

- for cycle: KEc: $\dot{W}_{\mathrm{NET}, \mathrm{c}}=\dot{W}_{\mathrm{TB}}-\dot{W}_{\mathrm{FP}}$

- for plant: K三p: $\dot{W}_{\mathrm{NET}, \mathrm{p}}=\dot{W}_{\mathrm{TB}}-\dot{W}_{\mathrm{FP}}-\left(\dot{W}_{\mathrm{HPP}}+\dot{W}_{\mathrm{FN}}\right)$

The exergy-based performances address the exergetic efficiency of the plant/components and the total exergy destruction ratio of the process units and subsystems. The calculation of these performances requires the determination of total exergy, mass free exergy and exergy destruction rates.

The chemical exergy of the stream is considered only in KLN plant and through the standard chemical exergy approach [13,71]. In the absence of chemical reactions in the plant, only the nonreactive exergy for ideal mixture is calculated. A compositiondependent component of chemical exergy is neglected due to its negligible influence on the overall balance [72]. Exergy destruction rates of operating units are obtained either through an exergy balance for the $\mathrm{CV}$ or by the entropy generation within the $\mathrm{CV}$ $[34,35]$. Exergy loss rates are neglected since the boundaries of CV-s are drawn at the ambient temperature. 
In the calculations of exergetic efficiency, an exception related to the dissipative component $\mathrm{AC}$ is made. According to the fuelproduct approach, AC is a dissipative component; thus, neither exergetic purpose nor exergetic efficiency for this component can be defined. Instead, the exergetic efficiency of this component is calculated in this paper according to the [73].

The economic performance of the plant is introduced through the total cost of equipment which is calculated by the following expression:

$C_{\mathrm{eq}}=\sum C_{\mathrm{base}, \mathrm{OU}} \cdot C_{\mathrm{qt}, \mathrm{OU}}$

where are:

- for heat exchange units, OU $\equiv \mathrm{HE}$ :

$C_{\text {base }, \mathrm{HE}}=580\left(\$ / \mathrm{m}^{2}\right)$

$C_{\mathrm{qt}, \mathrm{HE}}=\sum\left(A_{\mathrm{HE}}\right)^{0.8}, \mathrm{HE}=\{\mathrm{EV}, \mathrm{PH}, \mathrm{LTR}, \mathrm{HTR}, \mathrm{AC}\}$

- for power related units, Turbine $\mathrm{OU} \equiv \mathrm{TB}$ :

$C_{\text {base }, \mathrm{TB}}=4405(\$ / \mathrm{kW}), \quad C_{\text {base, }(\mathrm{FP}, \mathrm{HPP}, \mathrm{FN})}=1120(\$ / \mathrm{kW})$

$C_{\mathrm{qt}, \mathrm{PU}}=\sum(W \cdot \mathrm{PU})^{0.7}, \mathrm{PU}=\{\mathrm{TB}, \mathrm{HPP}, \mathrm{FP}, \mathrm{FN}\}$

In (8) $C_{\text {base }}(\$)$ is a base cost value and $C_{\mathrm{qt}}(\$)$ is a quotation from the experienced professional cost estimators [74]. Heat transfer surface area $\left(A_{\mathrm{k}}\right)$ is calculated by the LMTD method (for PH, LTR and HTR) and by the Effectiveness NTU method (for EV and AC) [75].

\subsection{Software verification and validation}

Software verification and validation (V\&V), illustrated by the flowchart in Fig. 5b, is carried out by assuming the same input of independent variables as in the reference plants. These values are presented with gold colour numbers in Appendix Fig. A1. The pressure change in the two new added process units, HPP and FN, are neglected to replicate the configurations of the reference plants (according to that, independent variable 5 is specified as a $2 \mathrm{MPa}$ and not $7 \mathrm{MPa}$ as in the base-case plant, etc.). The input values of unknown variables are estimated to increase the overall solution quality in the manner of a high agreement between the results of simulation and parameters in the reference plant.

The simulation outcomes are then compared with the corresponding thermodynamic properties and preferences of the reference plant. The agreement between these values is improved by the method of software calibration, primarily by changing the input of unknown variables in the subsequent simulations. In some cases, the value of independent variables used in the simulation is also changed due to additional improvement of agreement and due to restrictions in a solving procedure. For example, in KLN plant, independent variable number 9 (temperature of base mixture in state 2 ) differs from the corresponding variable in the reference plant owing to convergence problems with rich water-ammonia mixture in the state 5 . Furthermore, the fact that assumptions and procedures tied to the sequential modular calculations in Ref. [11] cannot be fully copied in the equation-oriented software is also a limiting factor of the softer validation.

The final results of $\mathrm{V} \& \mathrm{~V}$ procedure, where the maximum agreement is achieved for both plants, are presented in Fig. 6. The results are presented in the form of a percentage difference between the process quantities obtained by simulations and the corresponding values originating from the reference plant. The total percentage difference (TPD) is the average value of all investigated quantities. In authors' opinion, the results from the simulation software provide an acceptable agreement with the results from the reference plant. What is more, the percentage differences of energy and exergetic efficiency signify that thermodynamic performances of both plants are improved in respect to the reference plants.

\subsection{Software mode}

In the rest of the research, in respect to different design tasks and objectives, the plant simulators are partially modified and prepared for the use in two modes: design and parametric mode. Software flowcharts of both modes are presented in Fig. 7.

The design mode of a simulator (or design simulation) is associated to the single operating point of the plant. This mode enables a free input of all independent and unknown variables; due to that, it can easily be adjusted for the design of similar binary plants in other geothermal locations. A design simulation is primarily used for analysis and comparison of base-case plants as well as to investigate the influence of a type of a working fluid on ORC plant operation. Namely, the type of the working fluid in ORC plant is not a variable in the simulation task and its influence on plant performances can be examined only by comparing the preferences of the plants which operate under the same operating conditions. Because of that, performance analysis of ORC, related to the operations with different working fluids, is conducted by a series of design simulations which have the same input of all variables as the base-case plant.

The second, parametric mode (or parametric simulation) is related to the parametric analysis of binary plants. This kind of analysis is employed to investigate the influence of a single thermodynamic property on plant performances. The parametric analysis is supported by the simulation software which automatically solves entire ranges of property under investigation and generates the results which display performance trends necessary for identifying an optimal plant design. In the literature, parametric analysis is usually referred to as an analysis of the plant which operates in an off-design mode.

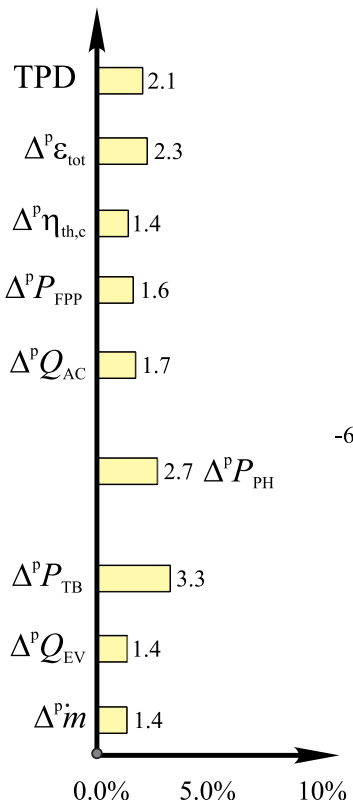

a)

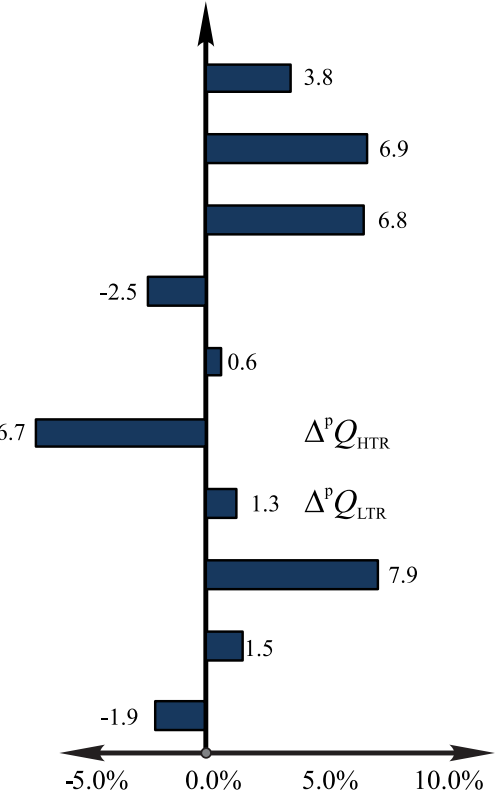

b)
Fig. 6. The results of software V\&V process. 


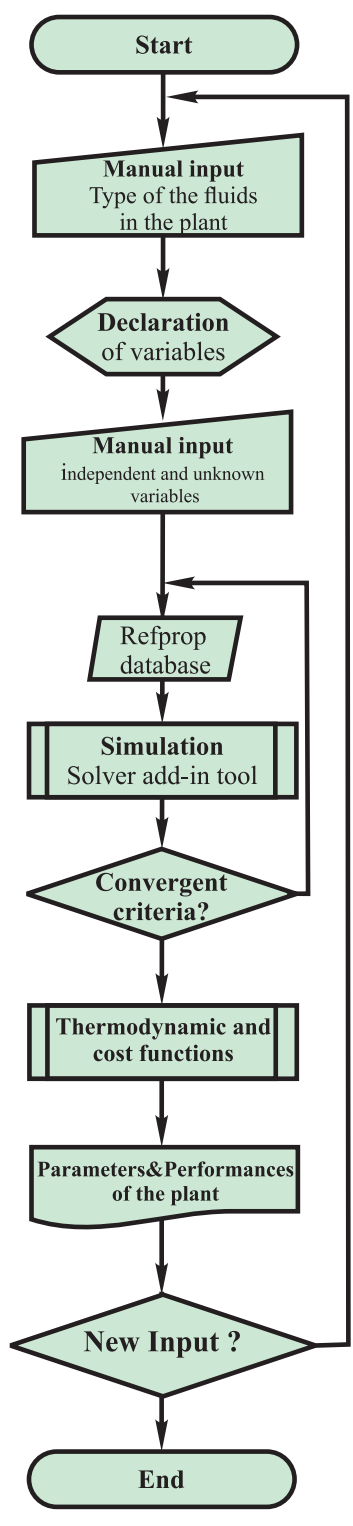

a)

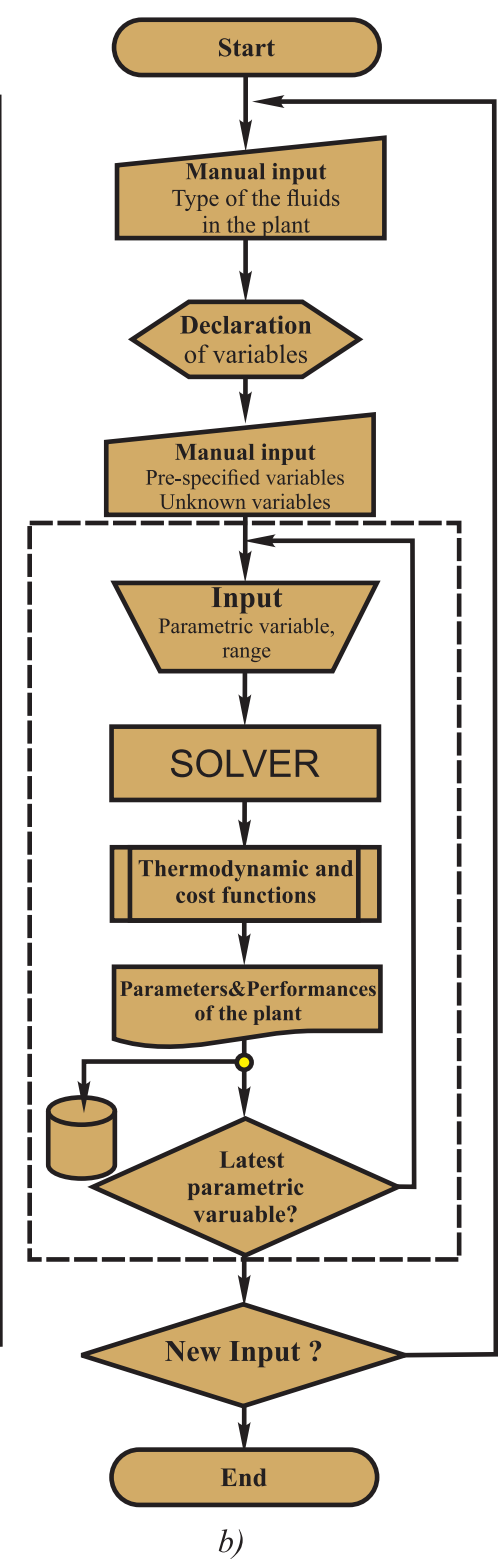

Fig. 7. Software flowcharts a) algorithm of design mode b) algorithm of parametric mode.

In the previously explained design software mode, the input of independent variables detects plant performances in a single operating point and this point can be changed only by different input of an independent variable in the next simulation. Furthermore, the new input is usually followed by the new estimation of an unknown variable and, as a result of these two procedures, the collection of data necessary for parametric analysis of the plant is slow and sometimes unreliable. For that reason, the software code of the existing design mode is modified to introduce a single simulation procedure of the plant which operates in the range of several operating points.

Modifications are initiated in the input part of the software where all independent variables are placed in two groups: parametric group and pre-specified group. As the name implies, the first, parametric group includes only an independent variable of interest, parametric variable. The other group involves all the other independent variables, and these variables are pre-specified variables.

In the next step, the inner, for loop, is added to the existing software code to enable multiple simulations under different inputs of a parametric variable. To distinguish that iteration cycle from the one present in the solver part of the software, its elements are prefixed by the attribute parametric. In Fig. $7 \mathrm{~b}$ it can be observed that parametric loop is framed by two modules: an input of parametric variable and exit criteria from the parametric cycle.

The incorporation of a parametric loop in the software code causes two important changes in the simulation procedure inside the simulator: one related to the input of a parametric variable and another related to the estimation of unknown variables. First, before the simulation starts, an input in the simulator has to determine the starting value of a parametric variable, its range of investigation and the number of iteration steps. Indirectly, the input can be set by the starting and ending value of a parametric variable. The starting value is commonly the lowest quantity inside the investigation range, while the ending value closes the parametric cycle. After that, the solving process starts inside the first parametric iteration and when it is complete, the results of the simulation are transferred to the external spreadsheet data-base table. In the subsequent iteration steps, the starting parametric variable is successively incremented by the value which is calculated as the ratio between the range of that variable and the number of iterations. The solving process is repeated and, after each iteration step, the results of simulations are collected in the successive columns of the data-base table.

In the previous design simulation, the estimation of unknown variables was carried out in the input part of the software and before the solving procedure. It is clear that the same sequence would interrupt the iterations inside the parametric cycle and, as a consequence, the parametric mode would be reduced to a simple design mode. For that reason, the estimation of unknown variables, as a mandatory task in equation-oriented simulations, is only performed before the start of the first iteration. In the subsequent iteration steps, the unknown variables in the current iteration get the values of the corresponding solutions from the previous iterations. By these two modifications, in every iteration step inside the parametric cycle, the operating point of the plant is determined only by the input of a parametric variable, while the pre-specified variables remain the same.

The results of all simulations carried out in one iteration cycle are stored in the data matrix table which is illustrated in Fig. 8a. The matrix format means that the data in the table are organized in the way that all rows have an identical number of columns, $m=1,2, \ldots \mathrm{M}$; and all columns have an identical number of rows, $n=1,2, \ldots \mathrm{N}$. Columns are titled by the values of a parametric variable $\left(p v_{\mathrm{m}}\right)$, while the rest of the cells contain the values of thermodynamic properties (other than the one used as a parametric variable), process quantities and performances of the plant, $\left(v l_{\mathrm{m}, \mathrm{n}}\right)$. In this way, the values in the cells are comparable across the rows and this characteristic is utilized in the parametric analysis of the plant.

In this paper, a parametric analysis is conducted to examine the relation between the parametric variables and some important performances of the plant: energy efficiency, exergetic efficiency and the total cost of the plant operating units. In the rest of the text, these three performances are called EEC performances in order to distinguish them from other performances which can be obtained by using the simulation software.

The parametric analysis is supported by graph based diagrams, and one of them is presented in the simplified form in Fig. 8c. The diagrams are created from the data stored in the modified table (Fig. 8b), which has the same format and identical heading (first row of the table) as a matrix table, but all the other values in its cells are modified using the functions of percentage differences [76]. The percentage difference of a single value $\left(\Delta^{\mathrm{p}} v l_{m, n}\right)$ in a modified table is calculated by the following expression: 


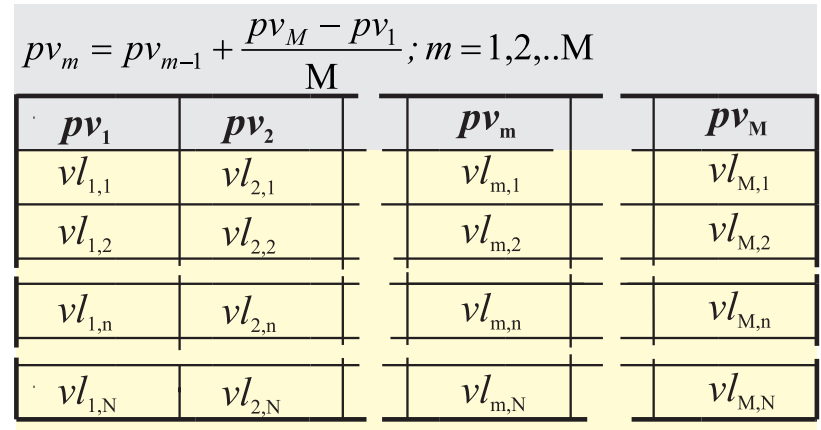

properties,process quantities and performances of the plant,

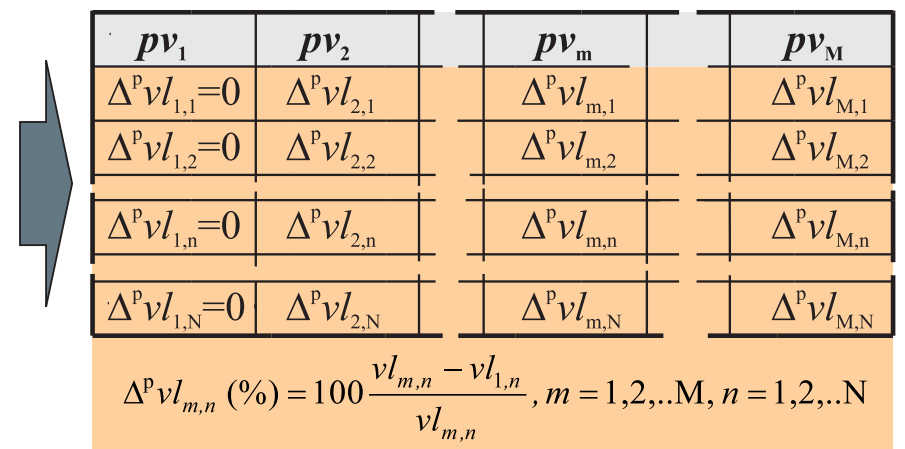

b)
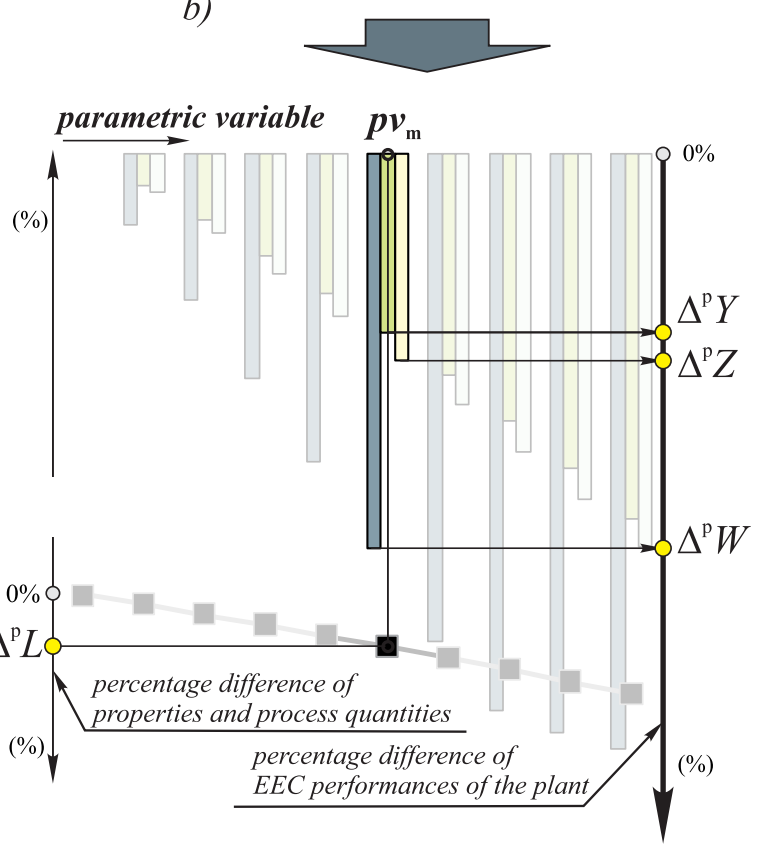

$\mathrm{L}, \mathrm{W}, \mathrm{Z}, \mathrm{Y} \in\left\{v l_{\mathrm{m}, 1}, v l_{\mathrm{m}, 2}, \ldots v l_{\mathrm{m}, \mathrm{N}}\right\}$

c)

Fig. 8. Graphical illustrations of data processing in parametric analysis of the plant.

$$
\Delta^{\mathrm{p}} v l_{m, n}(\%)=100 \frac{v l_{m, n}-v l_{1, n}}{v l_{m, n}}, m=1,2, \ldots \mathrm{M}, n=1,2, \ldots \mathrm{N}
$$

where $m$ and $n$ represent the column and row number in the table. If the value in the matrix table is measured in percentage, as for the energy or exergetic efficiency of the plant, the percentage difference represents a "so called" percentage point; otherwise it is a percentage change.

The values of a parametric variable inside the investigated range are put on the $x$-axis of a diagram, while the values of percentage differences associated to the EEC performances are presented as the bar charts whose elevation is referred to the primary $y$-axis, Fig. 8c. In this way, the bar charts manifest the trend in which EEC performances change with regard to the parametric variable along the $x$-axis.

Beside the bar charts, for the purpose of a clearer analysis, the percentage change of some process quantities is also introduced in diagrams in the form of line graphs. The points of line graphs are obtained in the same way as the elevation of bar charts and their values are referred to the secondary $y$-axis.
Similar graph based diagrams are also used for the performance analysis of the ORC base-case plant which operates with isopentane as the working fluid to investigate the type of a working fluid which could be an appropriate replacement for the isopentane. The design simulations of the base-case plant which operate with different working fluids generate a data-base table which has the same format and the same constitutive elements like the Matrix table which is used for the parametric analysis of the plant. The only difference is in the title of the columns; here, every column is labelled by the name of a working fluid, not the name of an investigated property. For that reason, the way the analysis is performed is the same as the one described above.

The second type of a diagram which supports the parametric analysis is an area chart-line type graph whose simplified form is presented in Fig. 8d. The diagram displays the percentage ratio of the exergy destruction generated in the operating units or in the subsystems and the total exergy destruction of the plant. The total exergy destruction ratio is commonly presented by an exergy pie chart (circle graph), but here the sectors from the pie chart are transformed in the vertical distance placed on the single ordinate. 
Each ordinate is associated to the parametric variable, $p v_{\mathrm{m}}$ as shown in Fig. 8d. Using the results from the matrix data table, the values of total exergy destruction rates on ordinates are collected in two ways: by using the area charts for process units (left diagram in Fig. 8d) and by using the thick lines for subsystems (right diagram in Fig. 8d). In this way, areas and lines show the trends of total exergy destructions in plant components over the investigated parametric variable. In the rest of the text, these types of graphs are named as total exergy destruction ratio (TEDR) diagrams.

\section{Base-case plants-design and analysis}

The simulation software is for the first time employed for the design and analysis of base-case plants, ORC and KLN. The main goal of the investigation was to compare plant performances in the case when they operate under the same conditions of energy source (geothermal water) and energy sink (cooling air).

The results of the simulation, concerning the thermodynamic properties in the plant, are presented as values in black colour in PFDs in Appendix Fig. A1. In the same PFD, the readers can indicate the independent variables which are used in the simulations and compare the properties of the plant with those which are obtained in Ref. [11] (these values are in gold colour).

The thermodynamic state points of the fluid streams in the base-case plants and processes in the operating units are visualized in the T-S diagrams in Figs. 9 and 10. Like in the reference plants, the working fluid in ORC plant is the low boiling-point isopentane$\mathrm{C}_{5} \mathrm{H}_{12}$ and in $\mathrm{KLN}$ plant it is an ammonia-water mixture. The temperature-entropy diagrams are composed of the base-case plants data and the skeleton diagrams of current fluids and mixtures. The skeleton diagrams are generated in the REFPROP software. In the case of ORC plant, the state points of geothermal water and cooling air are shifted along the $x$-axis for aesthetic reasons, but the real value of entropy in these points is readable on two additional abscissas. In KLN plant, a specific composition of the fluid in one state is coloured by the same colour as the corresponding saturated line of the mixture.

The parameters and preferences of plants related to the energy and economic analysis are displayed in the first two columns, labelled as ORC I and KLN, in the Table 1. As can be seen from the table, the energy efficiencies of a geothermal cycle, $\eta_{\mathrm{th}, \mathrm{c}}$ and geothermal plant, $\eta_{\text {th,p }}$ are higher in ORC plant. The main reason for such results arises from the differences in the turbine gross power $\dot{W}_{\mathrm{TB}}$, since other important parameters such as condensate pumping powers $\left(P_{\mathrm{FP}}\right)$, parasitic loads $\left(P_{\mathrm{HPP}}+P_{\mathrm{FN}}\right)$ and heat input in

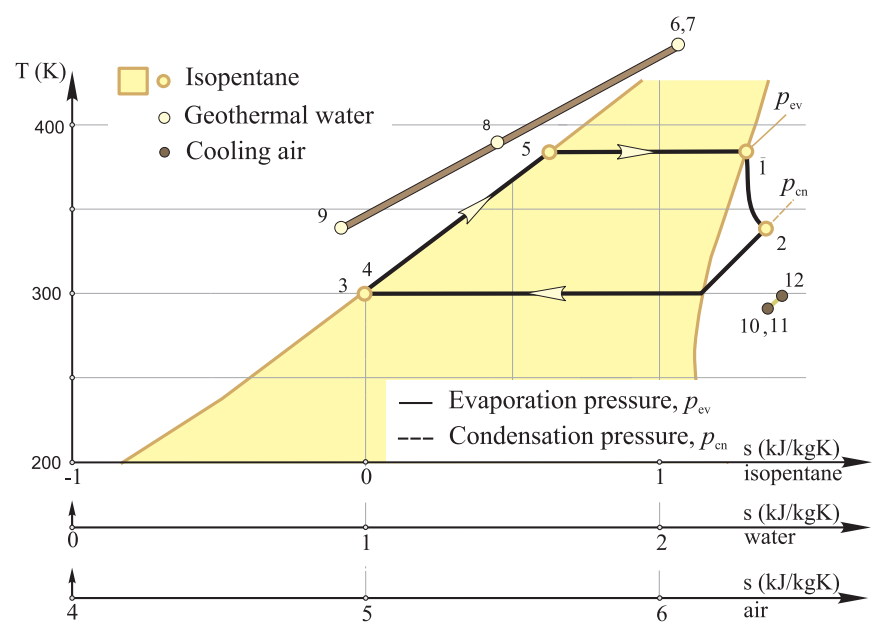

Fig. 9. Temperature-enthalpy diagram of base-case ORC plants.

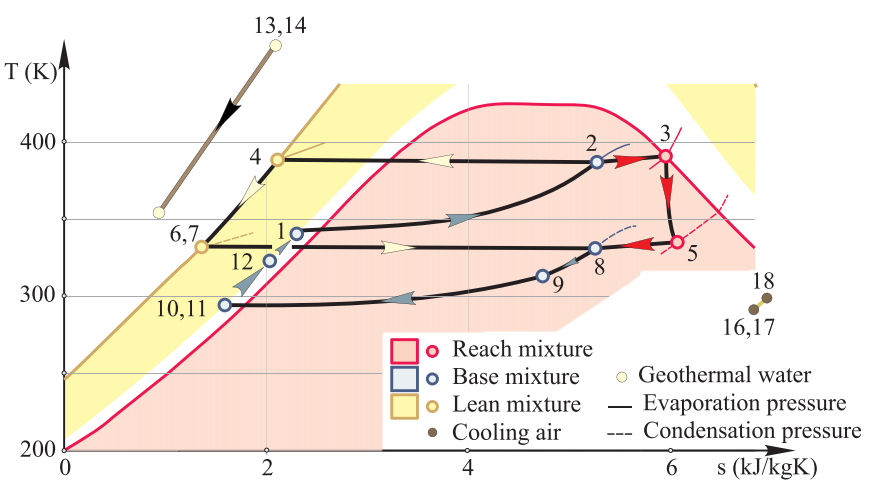

Fig. 10. Temperature-enthalpy diagram of base-case KLN plants.

the cycles $\left(\dot{Q}_{\text {IN }}\right)$ have similar values. Having the turbine power as a nonlinear function of a working fluid mass flow rate $\left(m_{\text {wf }}\right)$ and pressure drop in a turbine $\left(\Delta p_{\mathrm{TB}}=p_{\mathrm{ev}}-p_{\mathrm{cn}}\right)$, KLN plant operates with a substantially smaller mass flow rate and higher specific enthalpy drop $\left(\Delta i_{\mathrm{TB}}\right)$ in a turbine. The turbine cost in the ORC cycle is thus higher; on the other side, a high mass flow rate reduces the heat exchangers area in other operating units and hence reduces the cost of those units.

Following the conclusion that the energy efficiency of a plant primarily depends on the turbine gross power, in the next simulation, this quantity is decreased in ORC plant to be equal to the one in KLN plant. The new value is obtained under the same heat input in the cycles $\left(\dot{Q}_{\mathrm{IN}}\right)$ and by the decrease of evaporation pressure $\left(p_{\mathrm{ev}}\right)$ in the direction which reduces the pressure drop in a turbine. At the same time, the working fluid at the turbine inlet is kept in the saturated vapour state. For that reason, the declaration of variables is modified: the independent variable 6 is declared as an unknown variable, while the temperature of geothermal water in the state 9 has become a new independent variable (Fig. A1).

The performances obtained by the new simulation are presented in the third column, labelled as ORC II, of Table 1 . The corresponding energy efficiency of both plants is now almost the same but the mass flow rate of the working fluid in ORC plant is additionally increased, and consequently, the equipment cost in ORC plant is slightly decreased.

The overview of the most important information about the exergy flows through the geothermal plants is illustrated by the exergy flow diagrams in Figs. 11 and 12. At a glance, the sources of inefficiencies which are related to exergy destruction in ORC are almost equally distributed between the four process units (EV, TB, $\mathrm{PH}, \mathrm{AC}$ ) while it is obviously not the case in KLN plant. The rate of exergy destruction in the EV has the highest value in both plants,

Table 1

Parameters of the base-case plants used for energy and economic analysis (Small column size, $90 \mathrm{~mm}$ ).

\begin{tabular}{lrrr}
\hline \multicolumn{2}{c}{ ORC I } & KLN & ORC II \\
\hline$p_{\mathrm{ev}}$ & 0.90 & 2.80 & 0.57 \\
$p_{\mathrm{cn}}$ & 0.10 & 0.76 & 0.10 \\
$\dot{m}$ & 82.31 & 35.02 & 88.54 \\
$P_{\mathrm{TB}}$ & 5645.40 & 4646.90 & 4645.00 \\
$\Delta i_{\mathrm{TB}}$ & 68.59 & 158.87 & 52.46 \\
$P_{\mathrm{FP}}$ & 133.70 & 134.74 & 83.80 \\
$P_{\mathrm{HPP}}$ & 580.0 .94 & 580.09 & 580.0 .94 \\
$P_{\mathrm{FN}}$ & 653.30 & 667.11 & 672.00 \\
$\eta_{\mathrm{th}, \mathrm{c}}$ & 0.14 & 0.12 & 0.12 \\
$\eta_{\mathrm{th}, \mathrm{p}}$ & 0.11 & 0.09 & 0.09 \\
$Q_{\mathrm{in}}$ & $38,674.00$ & $38,376.66$ & $38,674.00$ \\
$\Sigma A_{\mathrm{PU}}$ & $16,206.70$ & $38,495.50$ & $18,548.20$ \\
$C_{\mathrm{n}}$ & $3,760,510.30$ & $5,074,322.70$ & $3,628,478.60$ \\
\hline
\end{tabular}




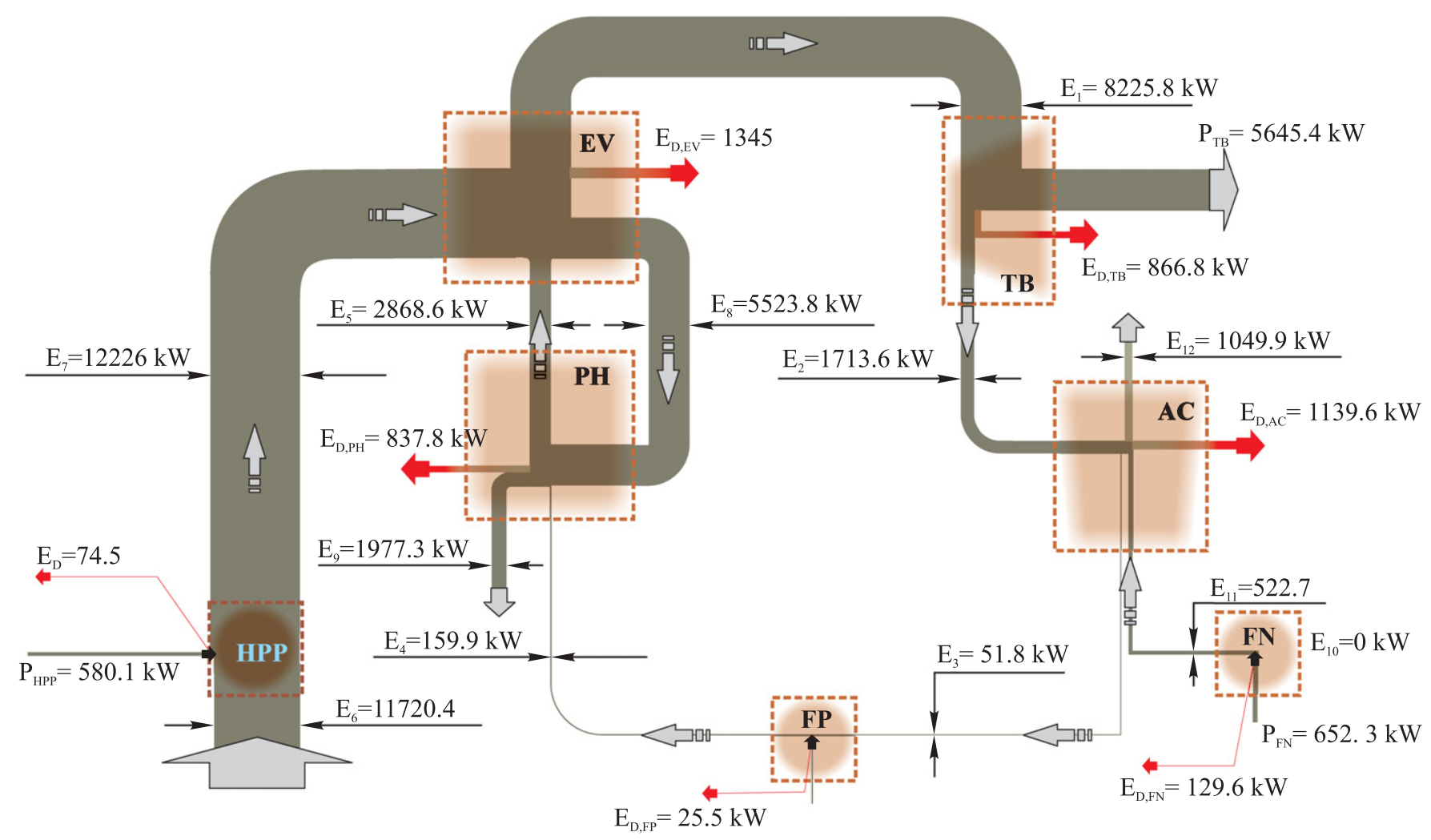

Fig. 11. Exergy flow diagram of ORC plant.

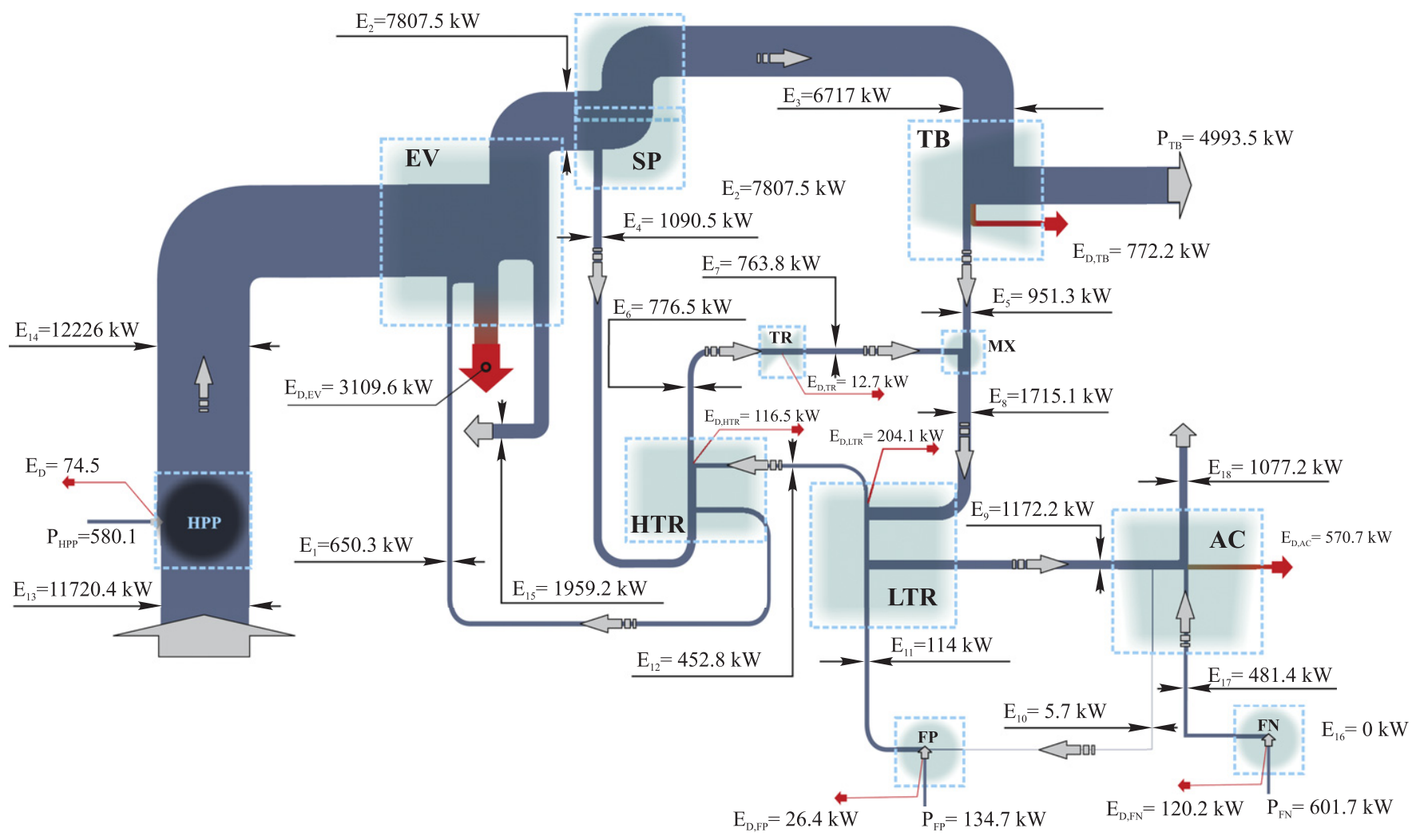

Fig. 12. Exergy flow diagram of KLN plant. 


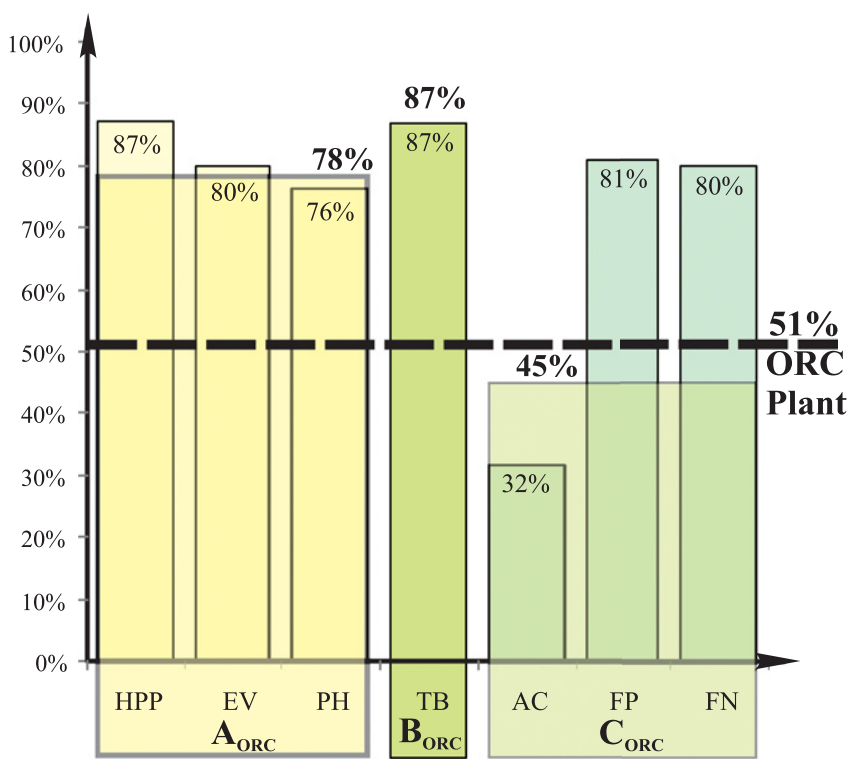

Fig. 13. Exergetic efficiency of ORC base-case plant.

but this value is more than two times higher in KLN plant. Furthermore, the rate of exergy destruction related to the energy input units (EV + PH in ORC, only EV in KLN) is also higher in KLN plant. On the other side, the magnitude of thermodynamic inefficiency in the energy rejection unit ( $A C$ in the both plant) is higher inside the ORC plant.

Quantification of exergy-based performances of the plants is performed by exergetic efficiency of the plant/components, and the total exergy destruction ratio of the process units and subsystems. Figs. 13 and 14 signify the exergetic efficiency of all process units, subsystems and a total plant.

The general observation is that exergetic efficiency of ORC plant is higher than KLN plant. Next, in ORC plant, the exergetic efficiency of the subsystem $A$ is higher than the subsystem $C$, while these performances of the subsystems are in different relation in KLN plant.

Additional analysis is shown in Figs. 15 and 16 where the total exergy destruction ratio of the process units is displayed in the

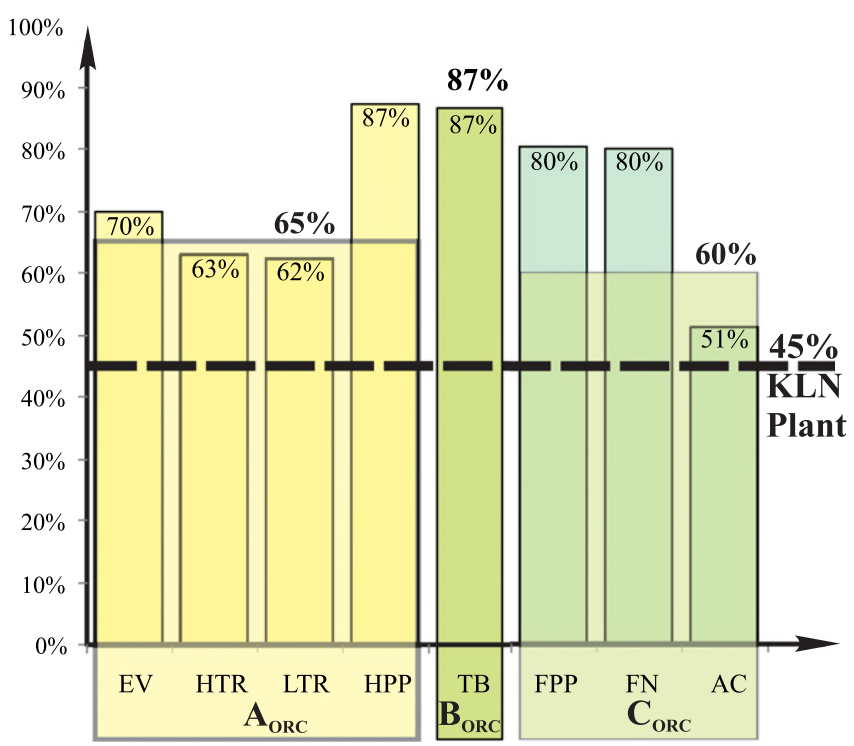

Fig. 14. Exergetic efficiency of KLN base-case plant.

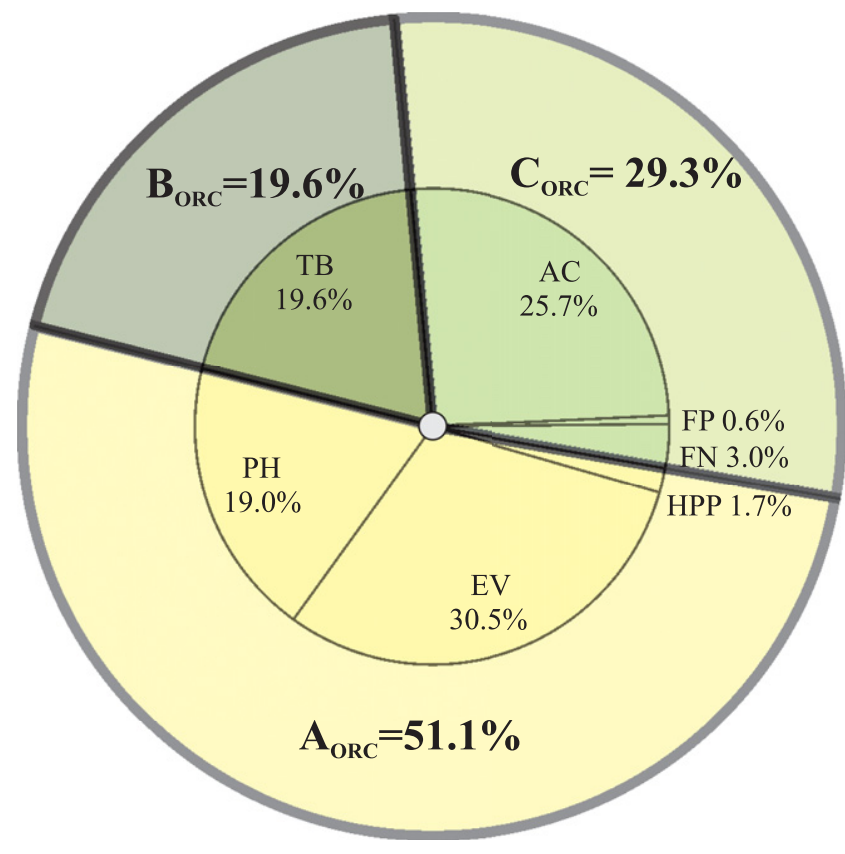

Fig. 15. Total exergy destruction rates in ORC base-case plant.

inner pie chart, while the total exergy destruction of the subsystems is presented in the outer part of the drawing. The results presented in these figures confirm the observations arising from the analysis of exergy flow diagrams.

The performance analysis of the base-case plants indicates that the plant design based on the ORC cycle has a higher thermodynamic efficiency and lower cost of equipment, and by that, it is more suitable for the future geothermal plant in Velika Ciglena. Apart from this conclusion, the performance analysis also exposes the most inefficient process units and parts of the plant and shows the directions for possible plant improvements. These directions will be additionally clarified by the parametric analysis presented in the next section of the paper.

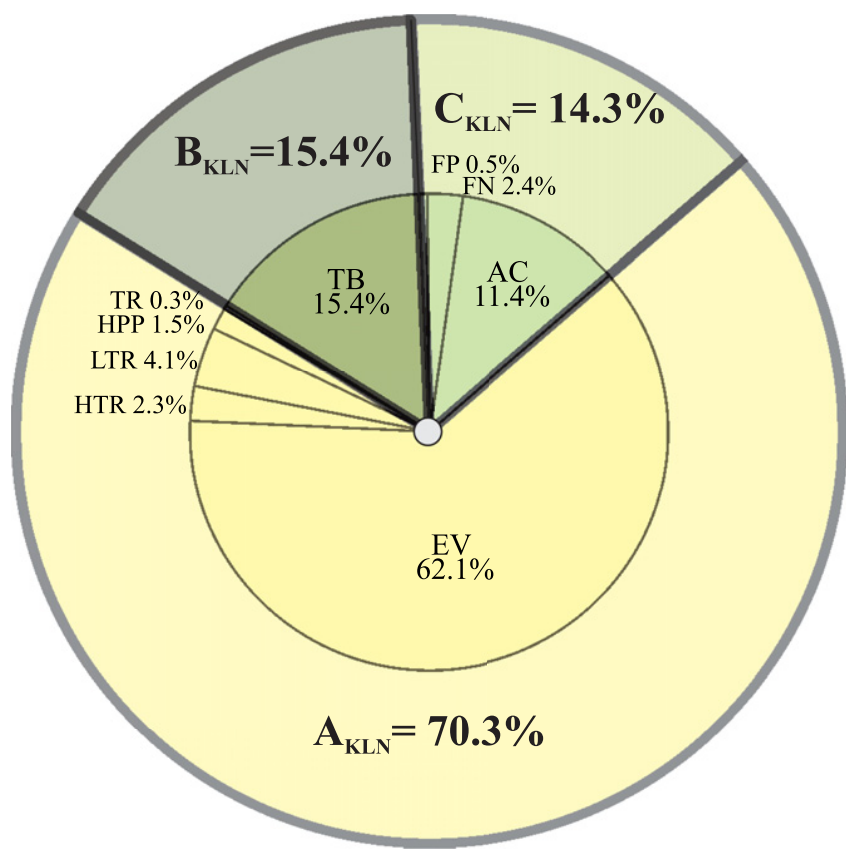

Fig. 16. Total exergy destruction rates in KLN base-case plant. 
Table 2

Properties of the investigated working fluids in ORC plant.

\begin{tabular}{|c|c|c|c|c|c|c|c|c|c|c|}
\hline Fluid type & $\xi(\mathrm{J} / \mathrm{kgK})$ & $r(\mathrm{~kJ} / \mathrm{kg})$ & $\rho_{\mathrm{lq}}\left(\mathrm{kg} / \mathrm{m}^{3}\right)$ & $\rho_{\mathrm{vp}}\left(\mathrm{kg} / \mathrm{m}^{3}\right)$ & $c p_{\mathrm{lq}}(\mathrm{kJ} / \mathrm{kgK})$ & $c p_{\mathrm{vp}}(\mathrm{kJ} / \mathrm{kgK})$ & $T_{\mathrm{ev}}(\mathrm{K})$ & $\Delta p_{\mathrm{TB}}(\mathrm{MPa})$ & $m(\mathrm{~kg} / \mathrm{s})$ & $P_{\text {net }}(\mathrm{KW})$ \\
\hline R141b & 0.00 & 222.71 & 1039.41 & 39.33 & 1.16 & 0.81 & 386.22 & 0.81 & 117.20 & 5040.24 \\
\hline R142b & 0.00 & 223.25 & 1011.87 & 39.65 & 1.23 & 0.82 & 334.14 & 0.52 & 222.03 & 3518.81 \\
\hline R123 & 0.26 & 170.19 & 1226.03 & 53.92 & 1.02 & 0.70 & 379.20 & 0.79 & 177.10 & 5358.67 \\
\hline $\mathrm{R} 245 \mathrm{ca}$ & 0.60 & 200.97 & 1170.63 & 48.56 & 1.33 & 0.93 & 371.68 & 0.78 & 168.20 & 5514.18 \\
\hline $\mathrm{R} 245 \mathrm{fa}$ & 0.19 & 196.05 & 1151.31 & 50.28 & 1.30 & 0.92 & 358.35 & 0.73 & 204.70 & 5184.25 \\
\hline Butane & 1.03 & 385.71 & 508.60 & 22.18 & 2.31 & 1.64 & 347.70 & 0.62 & 112.99 & 4561.00 \\
\hline Isobutane & 1.03 & 365.11 & 500.61 & 23.17 & 2.22 & 1.55 & 334.53 & 0.51 & 136.43 & 3632.80 \\
\hline Pentane & 1.51 & 357.59 & 510.77 & 24.90 & 2.37 & 1.76 & 392.62 & 0.82 & 67.49 & 5252.46 \\
\hline Ipentane & 1.37 & 343.29 & 513.26 & 25.44 & 2.29 & 1.71 & 383.51 & 0.80 & 82.31 & 5511.75 \\
\hline
\end{tabular}

5.1. Performance analysis of ORC base-case plant that operates with different working fluids

The simulation software in the design mode is also employed to investigate the possibilities for the use of different working fluids in ORC base-case plant. The selection method of working fluids is based on the thermodynamic criteria, and only the fluids with positive value of inverse-slope parameter, $\xi$, commonly named as "isentropic" $(\xi \approx 0)$ and "dry" $(\xi>0)$ fluids [77,78], are included in the analysis.

The main thermodynamic properties of the investigated fluids which are adopted from REFPRP data-base are placed in the first part of the Table 2 . The last three columns in Table 2 represent the properties and quantities which are obtained by a simulation using the design mode of the software.

The graph based diagram which is used for the performance analysis of ORC plant which operates with different working fluids is presented in Fig. 17a. The results of the simulations indicate that the EEC performances of the plants, which operate with pentane, $\mathrm{R} 141 \mathrm{~B}$, and R123 as working fluids, have the lowest values of percentage difference. This means that these three fluids can replace the isopentane as the working fluid in the base-case plant without any significant variations in EEC performances.

According to the data in Table 2, the elected fluids have similar evaporation temperature and produce almost the same pressure drop in turbine like isopentane. Due to that, the next design simulations are carried out by adjusting the base-case plant to operate under the same condensation pressure regardless of the type of the working fluid. However, as oppose to the evaporation pressure, the condensation pressure is not an independent variable in the basecase plant and, in new simulations, the declaration of variables has to be modified. The condensation pressure is declared as the independent variable, while the variable number 10 (minimum temperature differences in $\mathrm{AC}$ ) becomes the unknown variable. The results of the new simulations presented in Fig. 17b identify R123 as the most appropriate working fluid which could replace the isopentane in the base-case plant.

\section{Parametric analysis of ORC and KLN plant}

In this paper, the parametric analysis is conducted for the following variables:

- Composition of basic mixture in KLN plant, variable number 20, Fig. A1b;

- Environmental temperature, variable number 1, Fig. A1a and in Fig. A1b;

- Minimum temperature differences in AC, variable number 12 in Fig. A1a and Fig. A1b; and

- Evaporation pressure, variable number 6 in Fig. A1a and Fig. A1b.

The results of the simulations for each variable are presented in the graph based diagrams whose structure and composition are explained in the section four. The diagrams signify the trends of plant performances over the investigated range defined by the parametric variable and they enable the identification of the measures which could lead to the improvements of a plant design and operations. Also, the results of the simulations are employed for software testing under different combinations of inputs and preconditions.

Beside the fact that current simulation software could be easily converted into the optimization software (DOF $>0$ ), the optimization of the plant is not carried out in this paper. In authors' opinion, this task should be performed by addressing a wider range of property and performance analysis and more meaningful discussions, which could extend the paper to an inappropriate length. Consequently, some important considerations, especially in the case of KLN plant, are only outlined here with an indication that they will be presented in the following papers.

As an extension of the research about the influence of the working fluid on the plant operation, the first parametric simulation is performed in KLN plant. In contrast to the analysis which has been implemented in ORC plant where the investigation includes different types of pure fluids, the parametric analysis in KLN examines the relation between the composition of a base-case mixture and EEC performances of the plant.

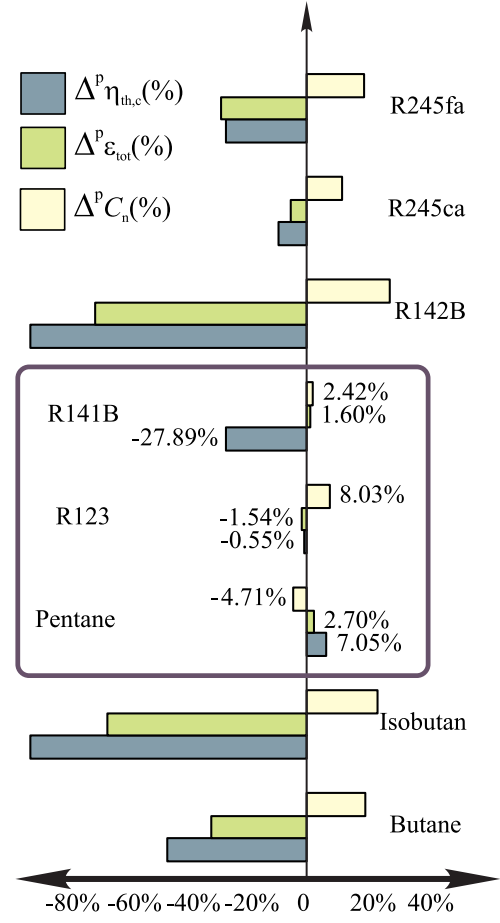

a)

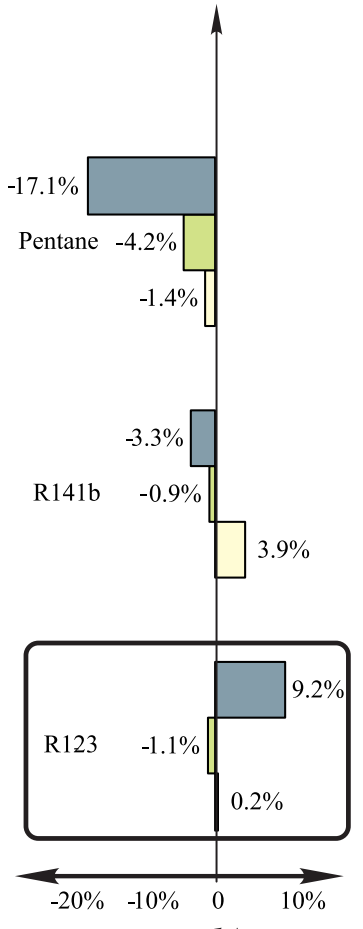

b)
Fig. 17. Performance analysis of the ORC plant which operates with different working fluids. 
The concentration of ammonia in the basic water-ammonia mixture is an independent variable in the base-case plant, and as a parametric variable it is investigated in the range of $88.5 \%-81.5 \%$.

The analysis of plant performances considers the results from the two parametric simulations. In the first pre-specified simulation, variables are specified in the way which enables simulations under the constant mass flow rate, and the results of those simulations are rearranged and presented by a graph based diagram in Fig. 18a. The second simulation assumes the constant heat input in the plant. The term heat input, $Q_{\text {in }}$, is the amount of heat which is transferred from the geothermal water to the cycle. The results of the second simulation are presented in Fig. 18b. In both diagrams, the percentage points of plant performances $\left(\Delta^{\mathrm{p}} \eta_{\text {th,c }}, \Delta^{\mathrm{p}} \varepsilon_{\text {tot }}\right)$ are referred to the bottom $x$-axis, while the percentage change of properties and quantities $\left(\Delta^{\mathrm{p}} p_{\mathrm{cn}}, \Delta^{\mathrm{p}} \mathrm{Q}_{\mathrm{in}}, \Delta^{\mathrm{p}} P_{\text {net,c }}, \Delta^{\mathrm{p}} m\right)$ are referred to the right $y$-axis. In both cases, the decrease of ammonia concentration has a positive effect on plant performances. These results are in agreement with a similar investigation performed by two co-authors in this paper; thus, for a detailed explanation and physical meaning of the results, the readers are referred to $[79,80]$.

Next parametric analysis investigates the influence of environmental temperature on EEC performances in both plants. Since the processes in the plants are assumed as adiabatic, the influence of environmental temperature is only related to the input temperature of ambient air in AC. This parametric variable signifies an independent variable number 11 (Fig. A1a and b). From the theoretical point of view, the ambient air temperature determines the condensation temperature of the working fluid, and through that, the condensation pressure in the plant. In the mathematical model of AC, the variable which determines the distance between condensation temperature and air ambient temperature is the $\Delta T_{\min }$ in $A C$ (number 12 in both plants, Fig. A1) and in the parametric simulation its value is set to $20^{\circ} \mathrm{C}$. The simulations are also performed under the constant mass flow rate of the working fluids in ORC plant, while in KLN plant the mass flow rate of the base mixture fluctuates in an acceptable range of $2 \%$.

The result of the parametric analysis for ORC plant is presented in Fig. 19 and for KLN plant in Fig. 20. The percentage points/change of plant performances $\left(\left(\Delta^{\mathrm{p}} \eta_{\text {th,c }}, \Delta^{\mathrm{p}} \varepsilon_{\text {tot }} / \Delta^{\mathrm{p}} C_{\mathrm{n}}\right)\right.$ is referred to the right $y$-axis, while the percentage change of properties and quantities $\left(\Delta^{\mathrm{p}} p_{\mathrm{cn}}, \Delta^{\mathrm{p}} Q_{\text {in }}, \Delta^{\mathrm{p}} P_{\text {net, }}, \Delta^{\mathrm{p}} m\right)$ is referred to the left $y$-axis.

In both plants, the increase of environmental temperature has negative effects on thermodynamic plant performances and it is primarily caused by the increase of condensation pressure. In ORC plant, due to the constants mass flow rate and fixed thermodynamic properties of isopentane in states 5 and 1, the increase of condensation pressure causes not only the reduction of energy input $\left(Q_{\text {in }}\right)$ and turbine gross power $\left(P_{\mathrm{TB}}\right)$, but also the growth of heat energy which has to be rejected from the plant. Thus, the amount of energy input is changed only by the reduction of the heat exchange duty in $\mathrm{PH}$, while the amount of rejected heat is the heat duty of AC. The results of the simulations also indicate that the increase of environment temperature reduces the total cost of equipment which can be considered as a positive trend in the process design.

Similar analysis trends can be observed in KLN plants, with a note that the use of a mixture as a working fluid adds a degree of freedom. The decrease of condensation pressure, under the constant evaporation pressure and fixed composition of base mixture, also reduces the concentration of ammonia in the streams where the composition of mixture is denoted as a rich mixture. For that reason, the influence of environmental temperature on plant performances is more pronounced in the case of KLN than in ORC plant.

This conclusion is additionally confirmed by the TEDR diagrams presented in Figs. 21 and 22. It is clear that the increase of environmental temperature in ORC plant only slightly modifies the contribution of exergy destruction in the components to the total exergy

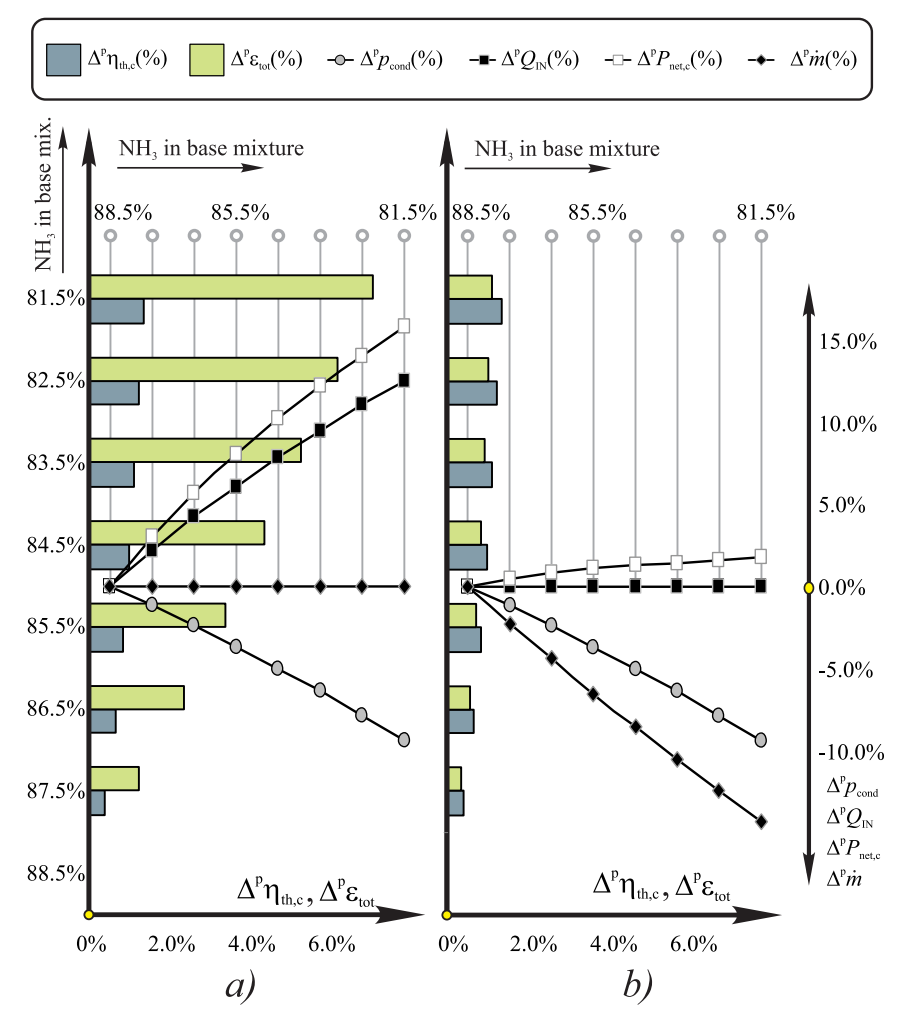

Fig. 18. Performance analysis of KLN plant; parametric variable: composition of base mixture.

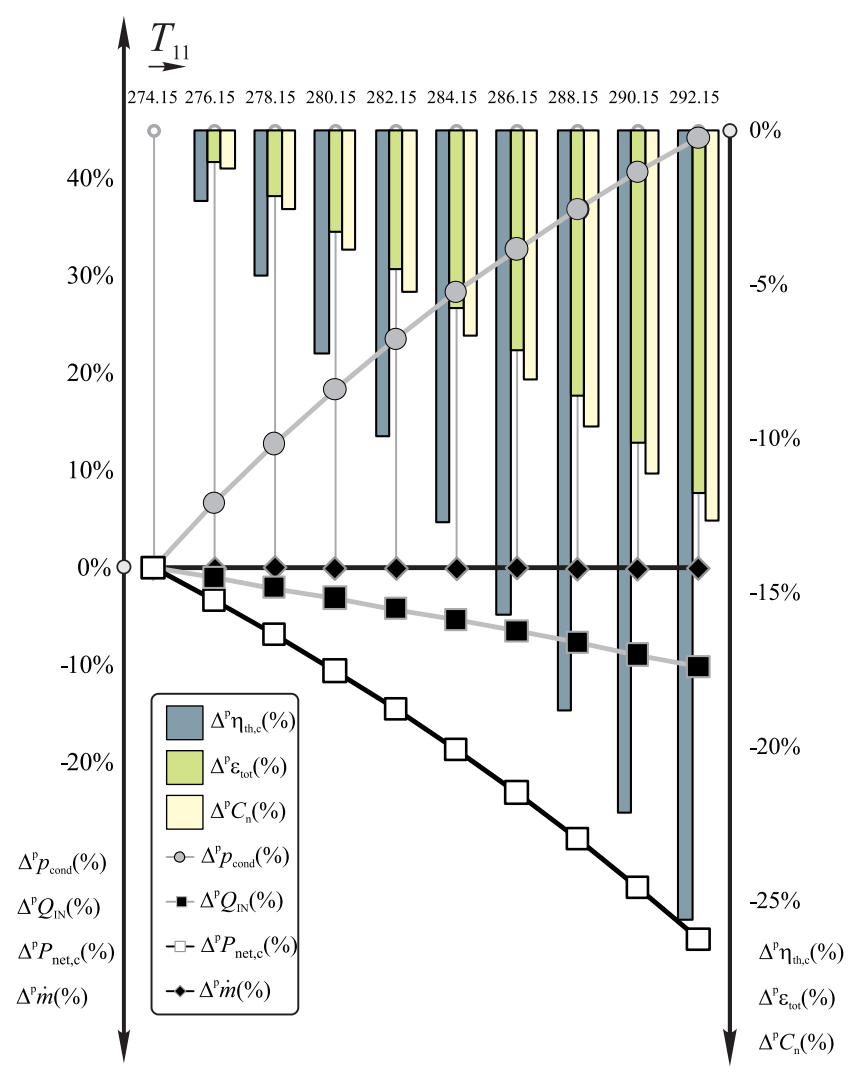

Fig. 19. Performance analysis of ORC plant; parametric variable: environmental temperature. 


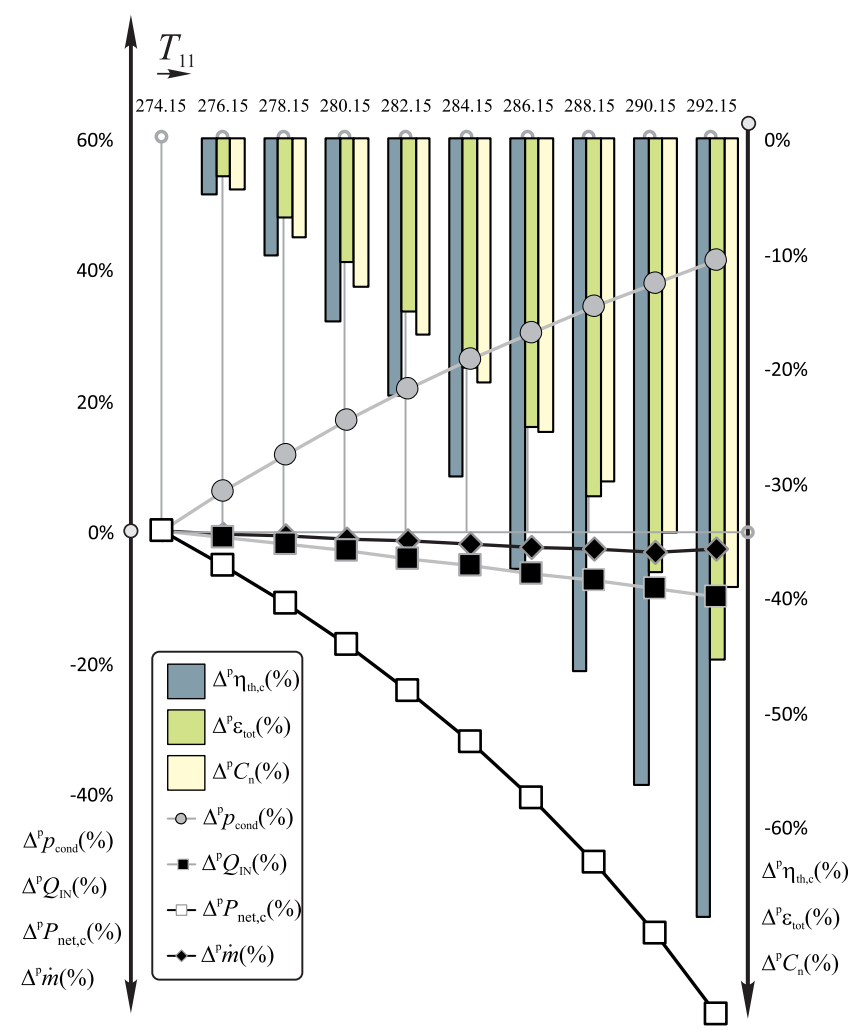

Fig. 20. Performance analysis of KLN plant; parametric variable: environmental temperature.

destruction in the plant over the investigated range. The situation is quite different in KLN plant. The source of exergy destruction shifts from $\mathrm{EV}$ to $\mathrm{AC}$ i.e. from subsystem $\mathrm{A}$ to subsystem $\mathrm{C}$.

In the next parametric simulation, the input temperature of cooling air in $\mathrm{AC}$ is declared as pre-scribed variable (number 11 in Fig. A1 a and b) assuming the value of $15^{\circ} \mathrm{C}$, the same as in the basecase plants. The new parametric variable is the minimum allowable temperature difference in $\mathrm{AC}$ in the range of $5^{\circ} \mathrm{C}-27.5^{\circ} \mathrm{C}$.

The parametric simulations are done under the same preconditions as in the case of the analysis devoted to the environmental temperature. Consequently, the EEC performances of the plant presented in Fig. 23 and 24 show the same trend since the increase of minimal temperature difference affects the system in a similar way as the increase of the inlet temperature of cooling air in AC.

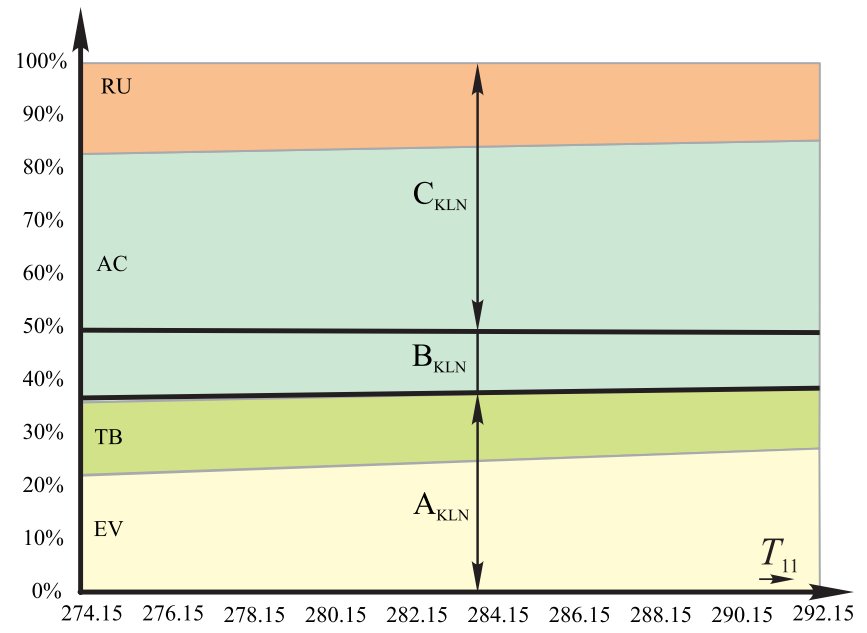

Fig. 21. TEDR diagram of ORC plant; parametric variable: environmental temperature.

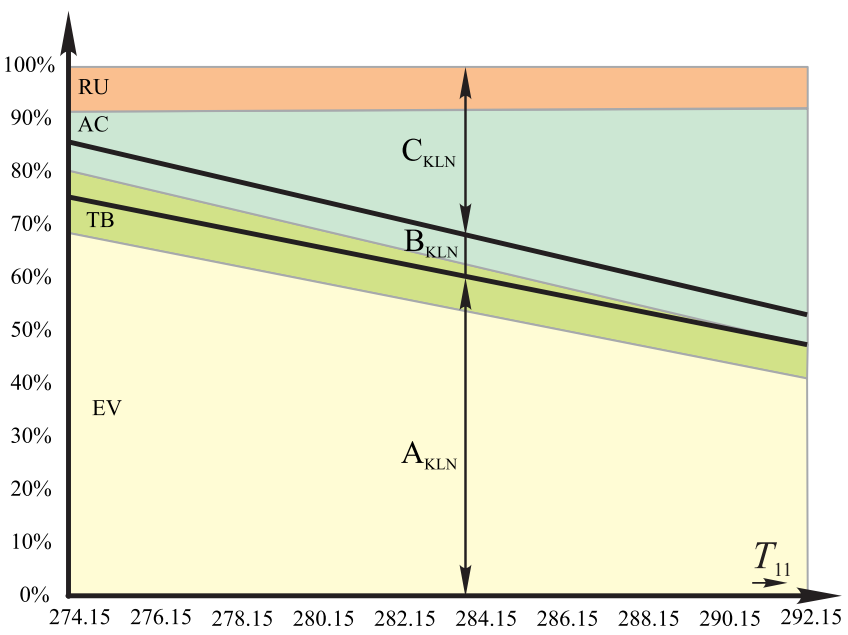

Fig. 22. TEDR diagram of KLN plant; parametric variable: environmental temperature.

The third parametric analysis investigates the relation between a new defined parametric variable-evaporation pressure and plant performances. Unlike the previous cases, the parametric variable in ORC plant has different values and ranges of investigation from those in KLN plants. For the current simulations, the condensation pressures in both plants are declared as independent, pre-specified variables and their values are adopted from the base-case plants (Fig. A1a and $b)$.

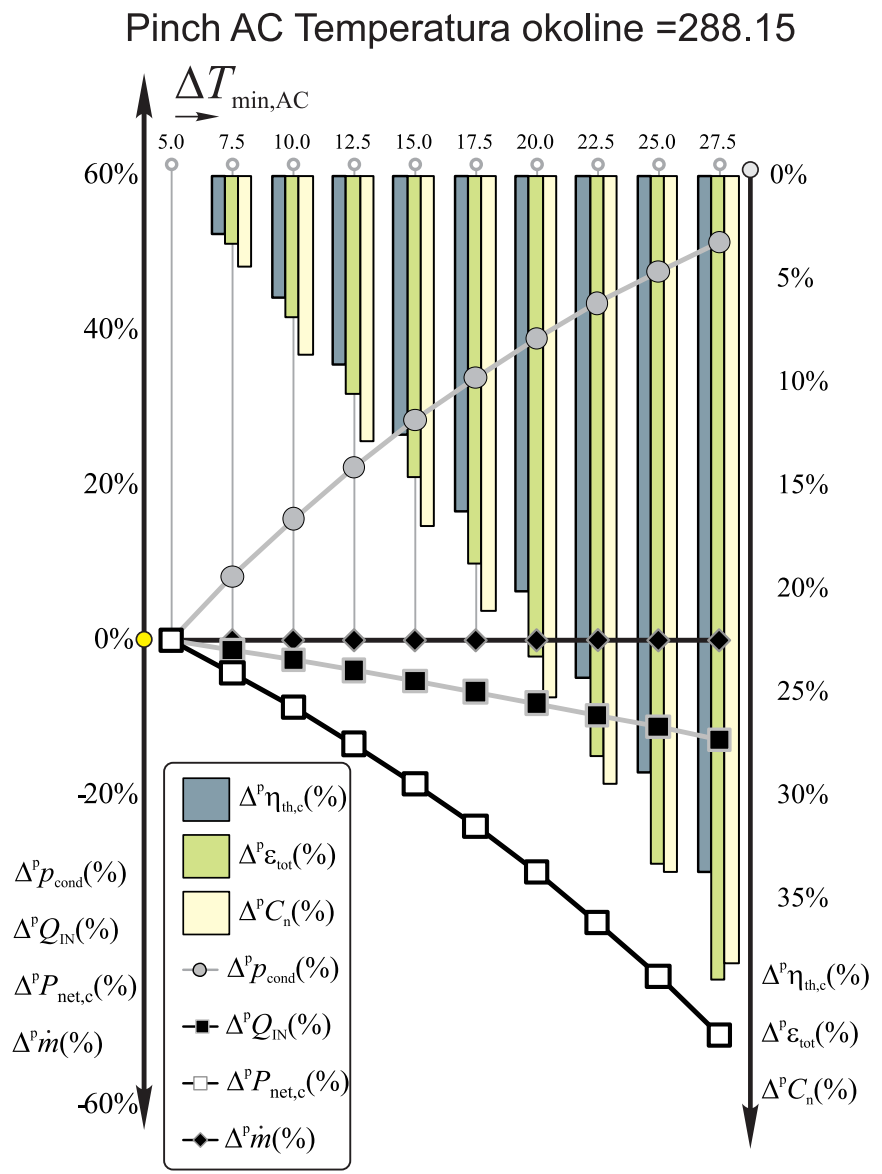

Fig. 23. Performance analysis of ORC plant; parametric variable: minimum allowable temperature difference in $\mathrm{AC}$. 
In the case of ORC plant, the decrease of evaporation pressure causes two effects in the state points which determine the process in EV (Fig. 9): the temperature of evaporation $\left(T_{5}\right)$ is reduced while the latent heat of evaporation $\left(h_{1}-h_{5}\right)$ is magnified. The results of the simulation also indicate the lower temperature of the geothermal water in the outlet of $\mathrm{PH}$, which means that the heat input $\left(Q_{\text {in }}\right)$ in the cycle slightly increases over the investigated range, Fig. 25. The lower outlet temperature of the geothermal water is determined by the constant value of $\Delta T_{\min }$ in $\mathrm{PH}$ (the same as in the base-case plant). On the other side, as a consequence of the energy balance of the ORC cycle, the increase of the heat input is followed by an almost constant value of the Turbine gross power (and by that, the minimal decrease of the net power in the cycle, $P_{\text {net,c }}$ ) and corresponding increase of the AC heat duty. New energy mapping of the plant, caused by the lower evaporation pressure in the cycle, increases the necessary mass flow rate of the working fluid in the plant $(\dot{m})$. Thermodynamic performances of the plant are inferior to the base-case plant, while the total cost of process units rises over the range of a parametric variable.

In the case of KLN plant (Fig. 26) where the evaporation pressure is considerably higher than in ORC, the decrease of that parametric variable is followed by the negative percentage difference of thermodynamic performances and net power in the plant. On the other side, it has a positive economic effect on the plant design (total cost of process units decreases).

In Fig. 27, TEDR diagram of ORC plant signifies that the total exergy destruction ratio of EV increases as the pressure of evaporation declines. At the same time, the shape which defines the total exergy destruction of the remaining operating units (RU) indicates decreasing trends. The diagram also indicates that the total exergy destruction rates between the subsystems remain almost the same

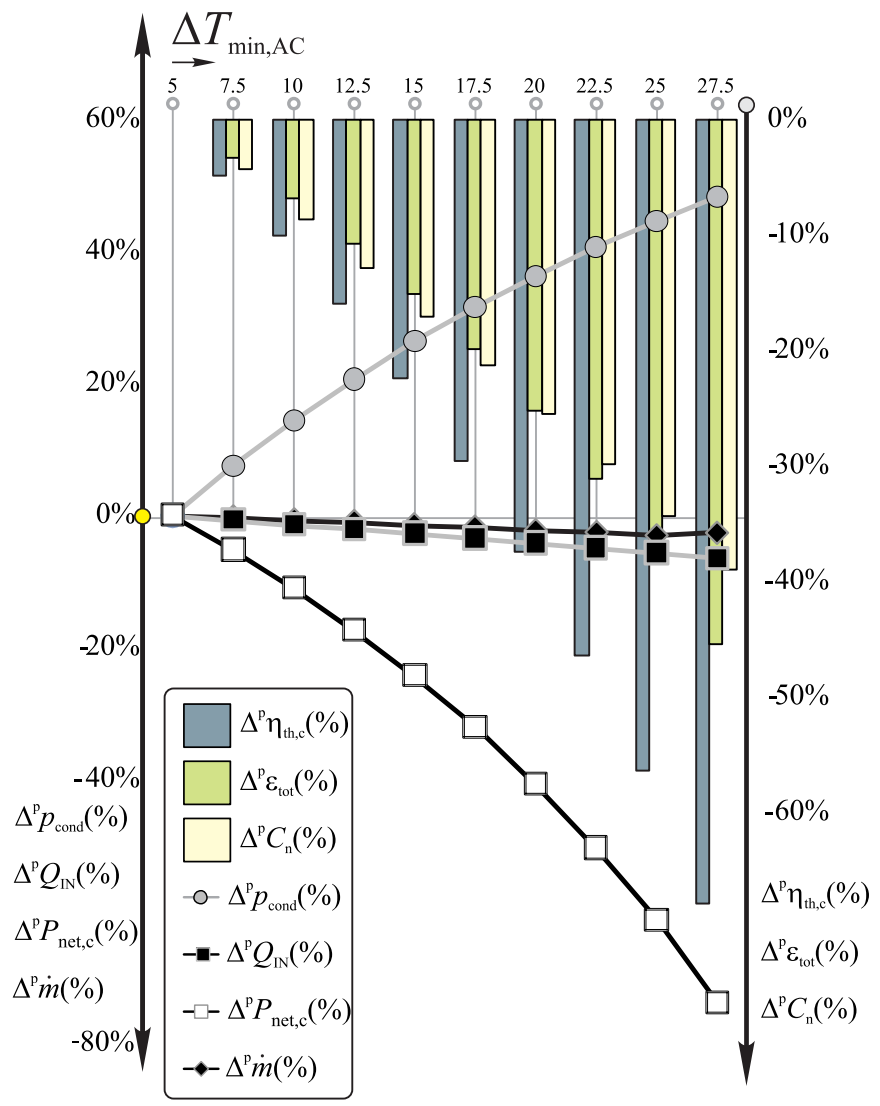

Fig. 24. Performance analysis of KLN plant; parametric variable: minimum allowable temperature difference in AC.

\section{Pritisak isparavanja Temperatura} okoline $=288.15$

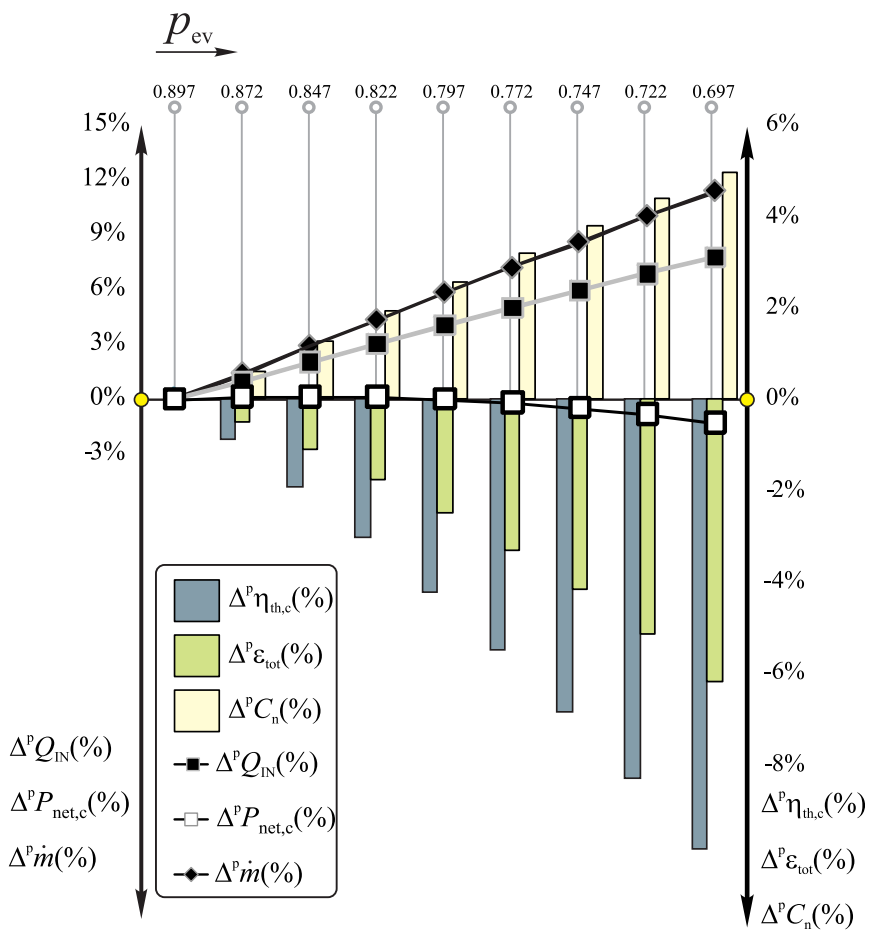

Fig. 25. Performance analysis of ORC plant; parametric variable: evaporation pressure.

over the investigated region of a parametric variable. These trends denote that exergy destruction rates change only in the two operating units, EV and $\mathrm{PH}$, while in the case of other operating units they remain almost the same. As it is displayed in Fig. 27, the amount of

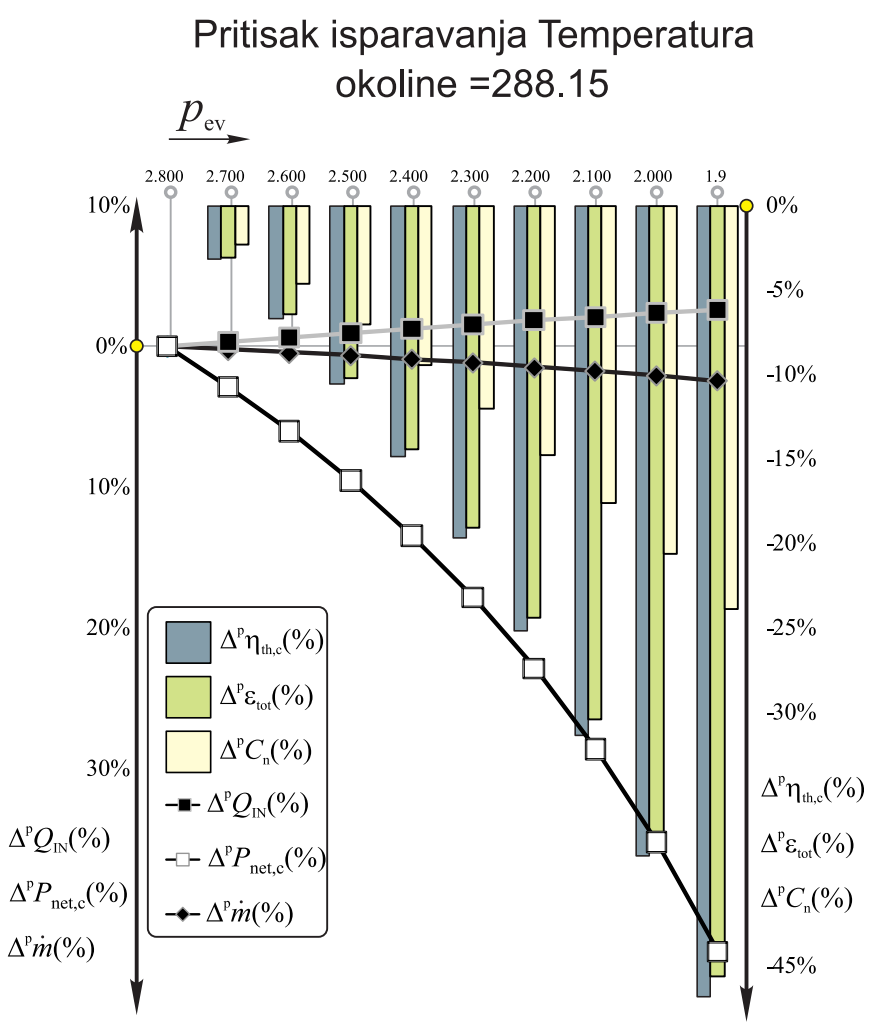

Fig. 26. Performance analysis of KLN plant; parametric variable: evaporation pressure. 


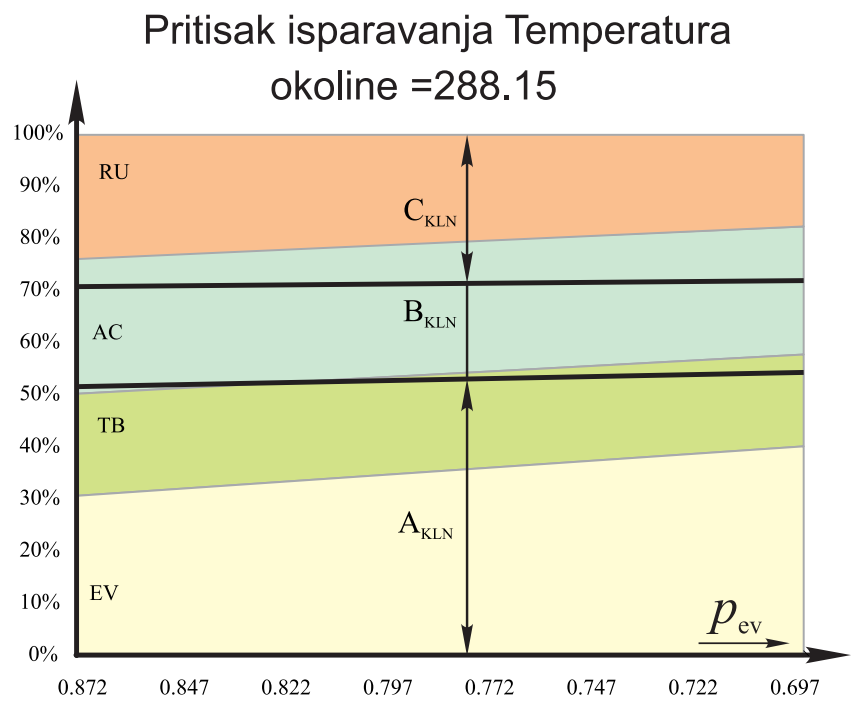

Fig. 27. TEDR diagram of ORC plant; parametric variable: evaporation pressure.

exergy destruction in $\mathrm{EV}$ and $\mathrm{PH}$, under different evaporation pressures in the plant, changes in opposite directions. However, the trend of exeretic efficiency in the plant, displayed in Fig. 25, indicates that the total amount of the exergy destruction in these operating units still increases.

The total exergy destruction diagram of KLN plant, presented in the Fig. 28, signifies that exergy destruction rate in TB increases over the investigated range. In this way, KLN plant which operates on the lower evaporation pressure causes two negative effects with regard to the base-case plant: the decrease of turbine gross power and increase of thermodynamic inefficiency in TB. Although it cannot be seen in Fig. 28, the decreasing evaporation pressure also inducts the growth of exergy destruction rate in AC.

The last two parametric analyses are conducted only in ORC plant. In the first, a parametric variable is the minimum allowable temperature difference between the geothermal water (hot streams) and the working fluid in the cycle (cold streams), where state 5 in the cycle defines the position of a pinch point for these streams. Theoretically, minimum allowable temperature difference determines the evaporation temperature of the working fluid in the cycle and indirectly its pressure of evaporation. According to that, the change of $\Delta T_{\min }$ influences plant performances in the same way

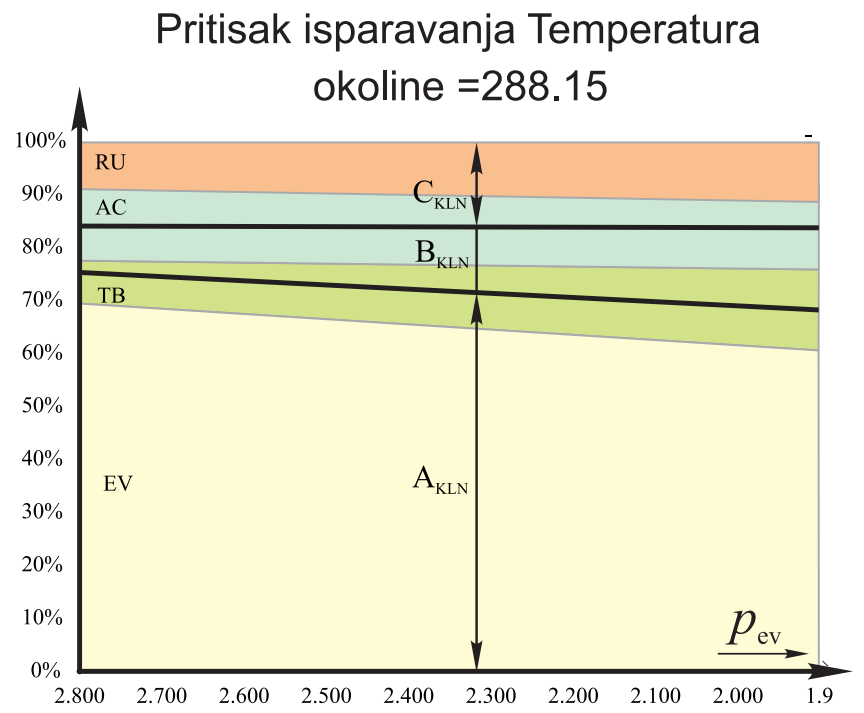

Fig. 28. TEDR diagram of KLN plant; parametric variable: evaporation pressure

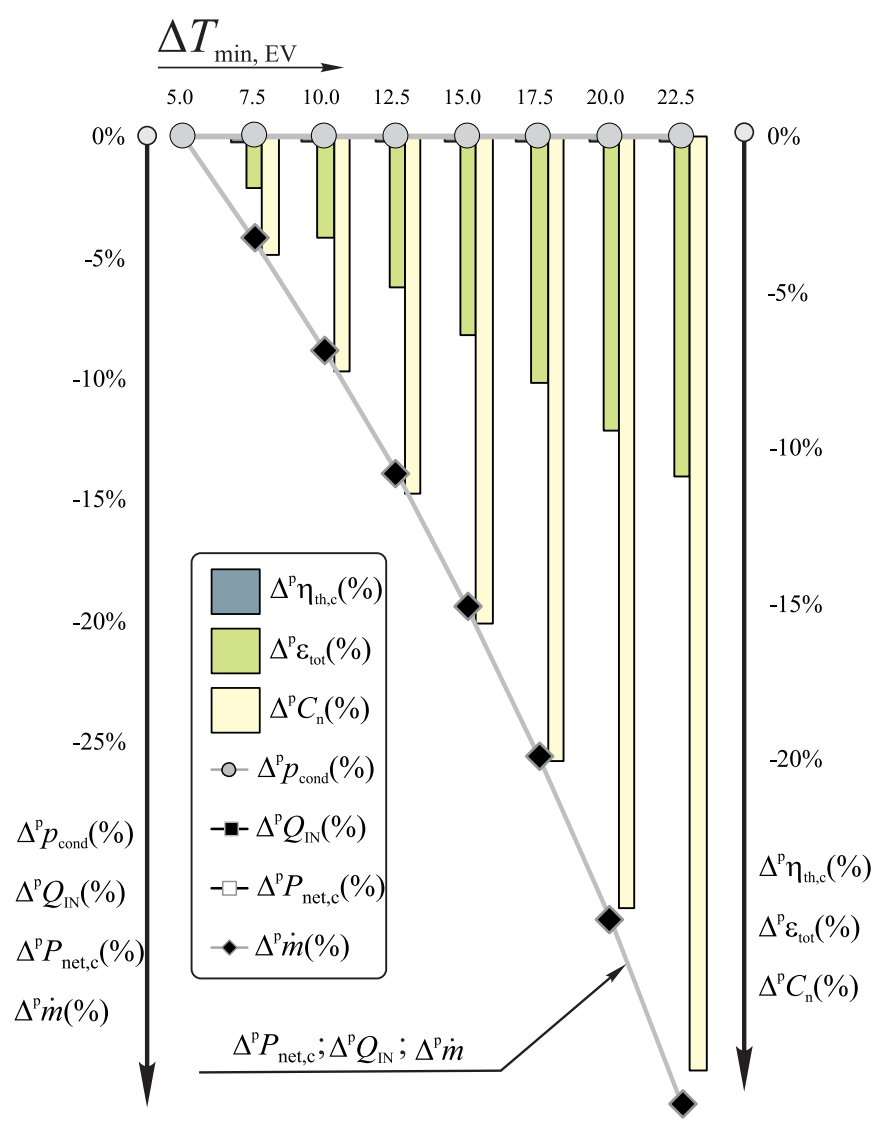

Fig. 29. Performance analysis of ORC plant; parametric variable: the minimum allowable temperature difference in $\mathrm{EV}$.

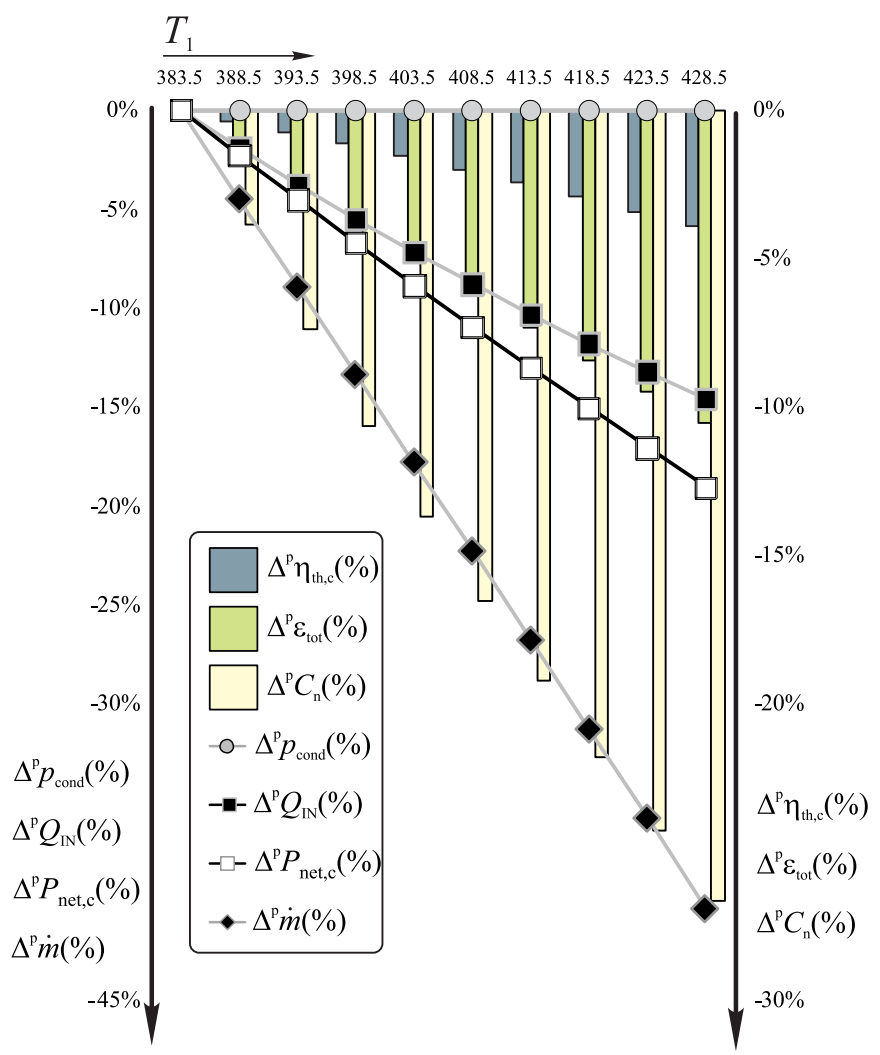

Fig. 30. Performance analysis of ORC plant; parametric variable: temperature of superheating. 
as the change of evaporation pressure does, which has been discussed in the previous analysis. For that reason, in the new parametric simulation, the evaporation and condensation pressure are pre-specified variables with values adopted from the base-case plant (Fig. A1a). In this case, the increase of $\Delta T_{\min }$ in EV reduces the heat input in the cycle and consequently the mass flow rate of the working fluid. Indirectly, following the energy balance of the plant, these modifications also decrease the turbine gross power and the amount of heat rejected from the plant. Mathematical consistency of the new simulation model is achieved by a different declaration of the variable number 12 (Fig. A1a), the minimum allowable temperature difference in AC.

The results of the simulations rearranged and presented in Fig. 29 indicate the identical graph of percentage differences vs. $\Delta T_{\text {min }}$ in EV for mass flow rate of working fluids, energy input and gross turbine power, and consequently the constant value of $\eta_{\mathrm{th}, \mathrm{c}}$ over the investigated range. As expected, the exergy efficiency of the plant is inferior to the base-case plant.

The second parametric analysis investigates the influence of superheating on plant performances. In the previous analysis, the working fluid in ORC plant evaporates until reaching the saturated vapour state, the cycle point 1 in Fig. 4. Following the practice of the traditional steam Rankine cycles where a higher degree of superheating increases the thermal efficiency of the plant, the evaporation process in ORC plant is extended in the region of superheated vapour. In the new parametric simulation, the outlet temperature from the evaporator becomes a new parametric variable. The evaporation and condensation pressure are declared as pre-specified variables and they are set on the same level as in the base-case plant. The parametric simulation assumes the constant heat duty in EV. This is also valid for other important elements of a plant design, especially for the minimum allowable temperature difference in Heat exchangers.

The results of the analysis presented in Fig. 30 signify the decrease of a working fluid mass flow rate with a higher degree of superheating. This trend is a consequence of energy balance in EV and constant value of $\Delta T_{\min }$ in the same operating unit. Additionally, the higher degree of superheating decreases the heat duty in PH and, consequently, the energy input in the cycle is reduced over the investigated region. The turbine gross power is reduced due to a lower mass flow rate and due to the fact that isopentane belongs to the group of in "dry" $(\xi>0)$ fluids. The thermodynamic performance of the plant which operates in the superheating regime is lower than in the basecase plant, while the total cost of process units is also decreased primarily due to the lower values of process quantities in the plant.

\section{Conclusion}

Geothermal field Velika Ciglena in Croatia is identified as one of the most valuable geothermal heat sources and probably the location where the first geothermal plant in the Western Balkan area will be built. The study presented in this paper involves the design and performance analysis of a binary geothermal plant which is proposed for the electricity generation in geothermal field in Velika Ciglena, Croatia. The research roadmap considers three coherent goals: the design of base-case binary plants, development of computer-aided design tools and performance analysis of the plants under several operating conditions. Despite the different research approaches, the final results of the design and analysis confirm the conclusion made in Ref. [11] that "ORC cycle is thermodynamically better, which can be explained by relatively high temperatures of geothermal water $\left(175^{\circ} \mathrm{C}\right)$ and of air for cooling $\left(15^{\circ} \mathrm{C}\right)$ ". This conclusion should be of great importance not only for the application of the binary plants in geothermal field Velika Ciglena, but also generally for other medium temperature geothermal sources, with similar geothermal properties and ambient conditions in Croatia and Serbia. The authors also propose that only a detailed thermodynamic analysis based upon the approach and methodology presented in this paper should be an essential practice for a geothermal plant design in all individual locations.

\section{Appendix}

Table A1

DOF analysis of ORC and KLN energy systems.

\begin{tabular}{|c|c|c|c|c|c|c|c|c|c|c|c|c|c|c|c|c|c|c|c|c|c|}
\hline \multirow{2}{*}{\multicolumn{2}{|c|}{$\frac{\text { System (Cycle) }}{\text { Component }}$}} & \multicolumn{8}{|c|}{ ORC (see Fig. 2a) } & \multicolumn{12}{|c|}{ KLN (see Fig. 2b) } \\
\hline & & EV & TB & $A C$ & $\mathrm{Fp}$ & HPP & $\mathrm{PH}$ & FN & System & EV & TB & $A C$ & $\mathrm{Fp}$ & HPP & HTR & LTR & TR & MX & SP & FN & Sys \\
\hline \multirow{10}{*}{$\begin{array}{l}N_{\mathrm{v}, \mathrm{k}} \\
N_{\mathrm{v}, \text { sys,tot }}, N_{\mathrm{v}, \text { sys,tot }}=\sum N_{\mathrm{v}} \text {, } \\
\text { Independent relations }\end{array}$} & & 14 & 11 & 22 & 11 & 11 & 14 & 12 & & 19 & 14 & 16 & 14 & 11 & 18 & 18 & 8 & 12 & 12 & 11 & \\
\hline & & & & & & & & & 95 & & & & & & & & & & & & 153 \\
\hline & Balance & & & & & & & & & & & & & & & & & & & & \\
\hline & Material & 2 & 2 & 4 & 2 & 2 & 2 & 2 & & 4 & 2 & 2 & 2 & 2 & 2 & 3 & 1 & 2 & 2 & 2 & \\
\hline & Energy & 2 & 2 & 4 & 2 & 2 & 2 & 2 & & 4 & 2 & 2 & 2 & 2 & 2 & 2 & 1 & 1 & 1 & 2 & \\
\hline & Number of sp & cifica & ons in & pose & on $\mathbf{t}$ & variab & & & & & & & & & & & & & & & \\
\hline & Pressure & 2 & 1 & 4 & 1 & 1 & 2 & 2 & & 4 & - & 2 & - & - & 3 & 2 & - & - & 2 & - & \\
\hline & Composition & - & - & - & - & - & - & - & & 2 & 2 & 1 & 2 & - & 2 & 3 & 1 & 2 & & - & \\
\hline & Temperature & 2 & 1 & 4 & 1 & - & 1 & - & & 1 & - & 1 & - & - & 1 & 1 & - & - & 2 & - & \\
\hline & Entropy & - & 1 & - & 1 & 1 & - & 1 & & - & 1 & - & 1 & 1 & - & - & - & - & - & 1 & \\
\hline \multicolumn{2}{|c|}{$N_{\mathrm{ID}, \boldsymbol{k}}$} & 8 & 7 & 16 & 7 & 6 & 7 & 7 & & 15 & 7 & 8 & 7 & 5 & 10 & 11 & 3 & 5 & 7 & 5 & \\
\hline \multicolumn{9}{|c|}{$N_{\text {ID,sys,tot, }}, N_{\text {ID,sys,tot }}=\sum N_{\text {ID, } k}$} & 58 & & & & & & & & & & & & 83 \\
\hline \multicolumn{21}{|l|}{ Redundant constrains } & 70 \\
\hline \multirow{9}{*}{$\begin{array}{l}N_{\mathrm{r}, \text { sys,tot }} \\
\text { Redundant relations }\end{array}$} & & & & & & & & & 24 & & & & & & & & & & & & 54 \\
\hline & Balance & & & & & & & & & & & & & & & & & & & & \\
\hline & Material & & - & - & - & - & 1 & - & & - & - & - & - & - & - & - & - & - & 2 & - & \\
\hline & Energy & & - & - & - & - & - & - & & - & - & - & - & - & - & - & - & - & - & - & \\
\hline & Number of sp & cifica & ons in & pose & on $\mathrm{tl}$ & variab & & & & & & & & & & & & & & & \\
\hline & Pressure & - & - & - & - & - & - & - & & - & - & - & - & - & 1 & - & - & - & - & - & \\
\hline & Composition & - & - & - & - & - & - & - & & - & - & - & - & - & - & 1 & - & - & - & - & \\
\hline & Temperature & - & 1 & - & 1 & - & - & - & & - & - & - & - & - & - & - & - & - & - & - & \\
\hline & Entropy & - & - & - & - & - & - & - & & - & - & - & - & - & - & - & - & - & - & - & \\
\hline \multicolumn{3}{|c|}{$\boldsymbol{N}_{\mathrm{RR}, \boldsymbol{k}}$} & 1 & & 1 & & 1 & & & & & & & & 1 & 1 & & & 2 & & \\
\hline \multicolumn{9}{|c|}{$\boldsymbol{N}_{\mathrm{RR}, \text { sys,tot }}, \boldsymbol{N}_{\mathrm{RR}, \mathrm{sys}, \text { tot }}=\sum \mathrm{N}_{\mathrm{RR}, \boldsymbol{k}}$} & 3 & & & & & & & & & & & & 4 \\
\hline \multicolumn{9}{|c|}{$\boldsymbol{N}_{\mathrm{DOF}, \text { plant }}, \boldsymbol{N}_{\mathrm{DOF}, \mathrm{cycle}}=\boldsymbol{N}_{\mathrm{DOF} \text {,sys,tot }}-\boldsymbol{N}_{\mathrm{r}, \text { sys,tot }}+\boldsymbol{N}_{\mathrm{RR} \text {,sys,tot }}$} & 16 & & & & & & & & & & & & 20 \\
\hline
\end{tabular}


*Legend

$\boldsymbol{N}_{\mathbf{v}, \mathbf{k}}$ Number of variables in component k.

$\boldsymbol{N}_{\mathbf{v}, \mathbf{s y s}, \text { tot }}$ Total Number of Variables in system.

$\boldsymbol{N}_{\text {ID, } \boldsymbol{k}}$ Number of Independent relations in component $k$.

$\boldsymbol{N}_{\text {ID,sys,tot }}$ Total Number of Independent relations in system.

$\boldsymbol{N}_{\text {DoF,k }}$ DOF in component $k$.

$N_{\text {Dof,sys,tot }}$ Total DOF in system.

$\boldsymbol{N}_{\mathbf{r}, \mathbf{s y s}, \text { tot }}$ Total number of redundant variables in interconnecting streams.

$\boldsymbol{N}_{\mathrm{RR}, \boldsymbol{k}}$ Number of redundant relations in component $k$.

$\boldsymbol{N}_{\mathbf{R R}, \mathbf{s y s}, \text { tot }}$ Total number of redundant relations in system.

$N_{\text {Dof,plant }}$ Overall DOF in plant.

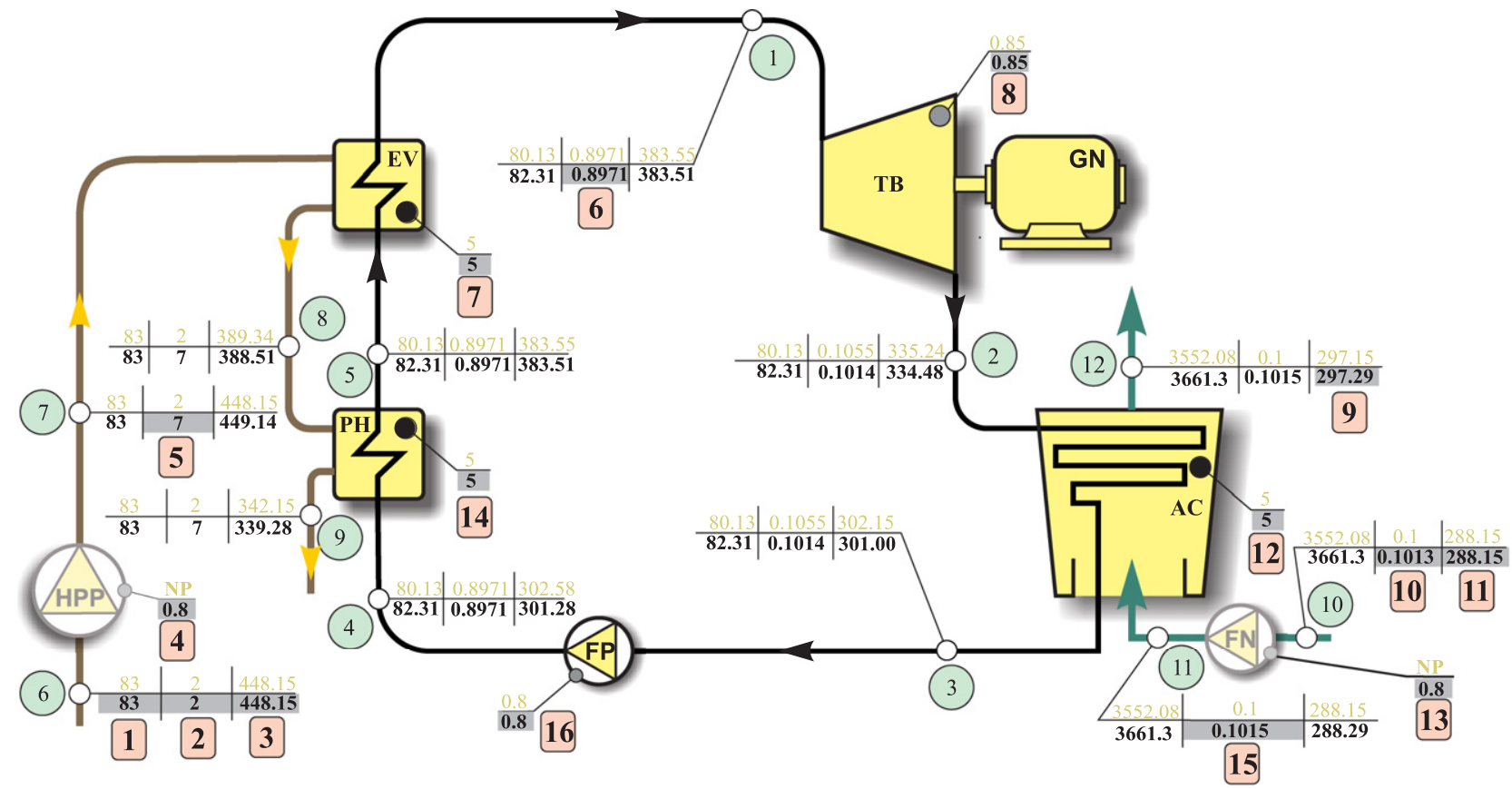

a)

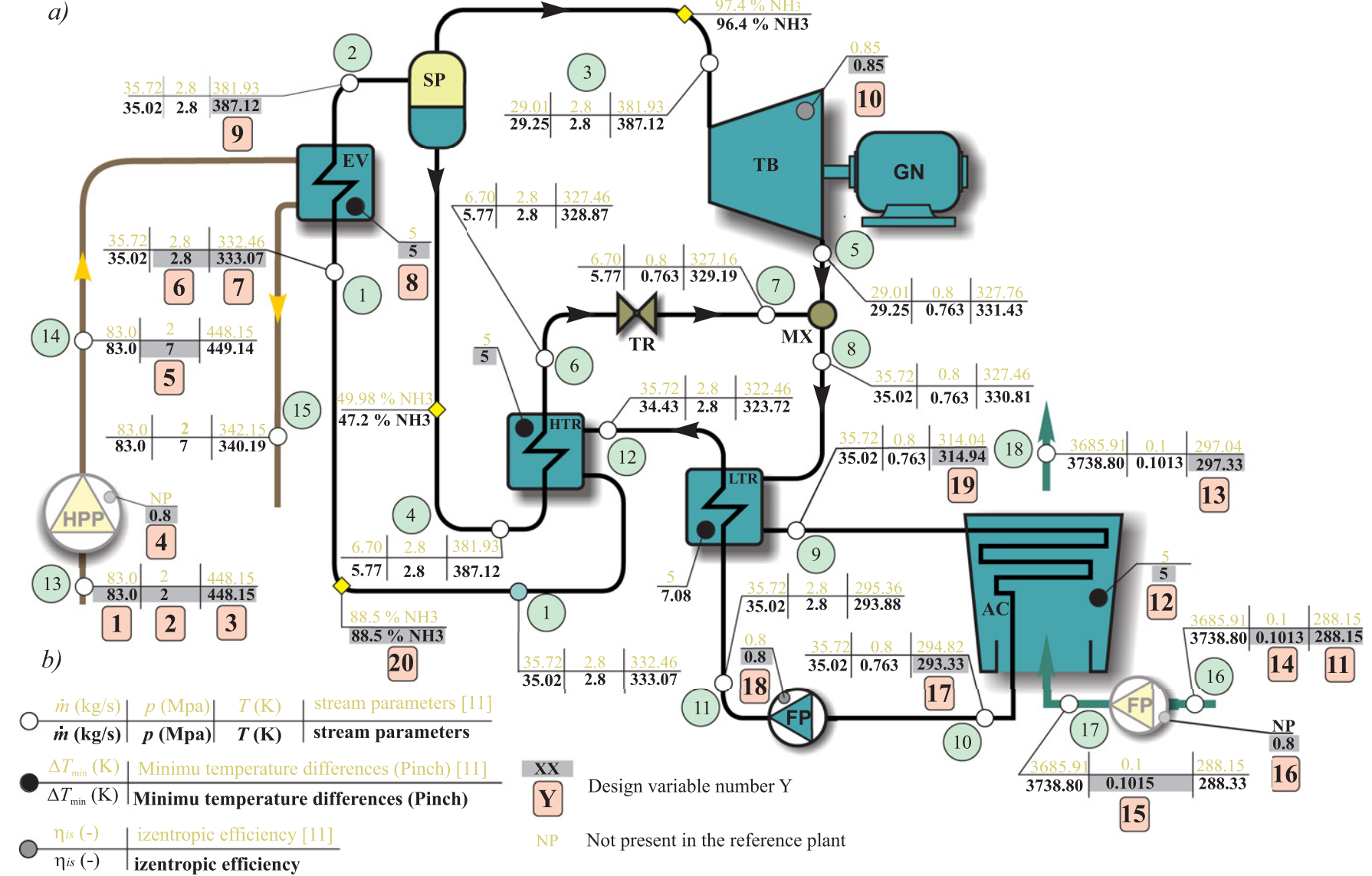

Fig. A1. Base-case plant, thermodynamic properties and declaration of variable. 


\section{Nomenclature}

$\begin{array}{ll}A & \text { area, } \mathrm{m}^{2} \\ C_{n} & \text { cost, } \$ \\ c p & \text { specific heat } \\ \dot{E} & \text { exergy flow rate, } \mathrm{W} \\ h & \text { specific enthalpy, } \mathrm{J} / \mathrm{kg} \\ H & \text { enthalpy, J } \\ \dot{m} & \text { mass flow rate, } \mathrm{kg} / \mathrm{s} \\ n & \text { number of system components } \\ p & \text { pressure, Pa } \\ r & \text { latent heat, } \mathrm{kJ} / \mathrm{kg} \\ \dot{Q} & \text { heat flow rate, } \mathrm{W} \\ S & \text { specific entropy, } \mathrm{J} / \mathrm{kgK} \\ \dot{S} & \text { entropy flow rate, } \mathrm{W} / \mathrm{K} \\ \dot{W}, P & \text { power, W } \\ \Delta T_{\text {min }} & \text { minimum allowable temperature difference, }{ }^{\circ} \mathrm{C}\end{array}$

\section{Abbreviations}

\section{A, B, C subsystems}

$\mathrm{AC}$ air condenser

CV control volume

DOF degree of freedom

EV evaporator

FN fan

FP feed pump

GN generator

HE heat exchanger

HPP high pressure pump

HTR high temperature heat exchanger

IW injection well

KLA Kalina cycle

LTR low temperature heat exchanger

MX mixing unit

ORC Organic Rankine cycle

$\mathrm{PH} \quad$ preheater

PU process unit

pv parametric variable

TB turbine

TR throttling valve

PW production well

SP separator

$v l \quad$ value

\section{Greek symbols}

$\begin{array}{ll}\Delta & \text { rate of change } \\ \Delta^{\mathrm{p}} & \text { rate of percentage differences (\%) } \\ \varepsilon & \text { exergetic efficiency } \\ \eta & \text { efficiency } \\ \xi & \text { inverse-slope parameter, J/kgK } \\ \rho & \text { density }\end{array}$

\section{Subscripts and superscripts}

c cycle

cn condensation

CV control volume

D destruction

DOF degree of freedom

ev evaporation

gen generated

in inlet

$\mathrm{k}$ component of the system

L loss

lq liquid

mix mixture

$\begin{array}{ll}\text { NET } & \text { net } \\ \text { out } & \text { outlet } \\ \mathrm{P} & \text { product } \\ \text { sys } & \text { system } \\ \text { th } & \text { thermodinamic } \\ \mathrm{T} & \text { thermal } \\ \text { tot } & \text { total }\end{array}$

\section{References}

[1] Antics M, Sanner B, editors. Status of geothermal energy use and resources in Europe. In: Proceedings of the European Geothermal congress. Germany; 2007; Unterhaching.

[2] IEA-Technology Roadmap Geothermal Heat and Power [Internet]. International Energy Agency [cited 2011 Jun 6]. Available from: http://www.iea.org/ papers/2011/Geothermal_Roadmap.pdf.

[3] Axelsson G, Gudmundsson A, Steingrimsson B, Palmason G, Armansson H, Tulinius $O$, et al. Sustainable production of geothermal energy: suggested definition. IGA News 2001;43:1-2.

[4] Special Report on Renewable Energy Sources and Climate Change Mitigation [Internet]. Intergovermental panel on climate change [cited 2011 Jun 15]. Available from: http://www.ipcc-wg3.de/publications/special-reports.

[5] Integrated energy policy report. Sacramento (CA): California Energy Commission; 2007. Report No.:CEC-100-2007-008-CMF.

[6] Doroodchi E, Behdad Moghtaderi B. State-of-the-art in power cycles for geothermal applications and bottoming cycles. Department of Primary Industry and Resources South Australia (PIRSA); 2009.

[7] Kovačić M. Geothermal resources utilisation in the Republic of Croatia in the year 2000, vol. 41. Pisa, Italy: IGA News, Newsletter of the International Geothermal Association; 2000. p. 5-6.

[8] Jelic K, Kovacic M, Koscak-Kolin S. State of the art of the geothermal resources in Croatia in the year 2004. In: Proceedings of the World geothermal congress 2005. Antalya, Turkey; 2005.

[9] The web application [cited 2011 Aug 19]. Available from: http://www. geoville.com/renewables

[10] Bošnjak R, Čubrić S, Golub M, Grabovski K, Jelić K, Kolin I, et al. A program of geothermal energy usage in the Republic of Croatia. Zagreb, Croatia: Energy Institute "Hrvoje Požar" [cited 2011 Jul 15]. Available from: http://www.eihp. hr; 1998.

[11] Guzovic Z, Loncar D, Ferdelji N. Possibilities of electricity generation in the Republic of Croatia by means of geothermal energy. Energy 2010;35(8):3429-40.

[12] Valero A. Exergy accounting: capabilities and drawbacks. Energy 2006;31(8): 164-80.

[13] Bejan A, Tsatsaronis G, Moran M. Thermal design and optimization. New York: Wiley; 1996.

[14] Szargut J, David RM, Steward FR. Exergy analysis of thermal, chemical and metallurgical processes. Berlin, Germany: Springer-Verlag; 1988.

[15] Kotas TJ. The exergy method of thermal plant analysis. Reprint Edition. Malabar (FL): Krieger; 1995.

[16] Gong M. Using exergy and optimization models to improve industrial energy systems towards sustainability [dissertation]. Linkoping, Sweden: Linkoping University; 2004. Dissertation No.: 868; ISBN 91-7373-933-2; ISSN 0345-7524.

[17] Gibbs JW. A method of geometrical representation of thermodynamic properties of substances by means of surface. Trans Connecticut Acad 1873;II: $382-404$.

[18] Jouget E. The theorem of Mr. Gouy and some of its applications. Rev Mech 1907;2:213-38. [French].

[19] Bošnjaković F. Fight against irreversibilities. Arch Wärmewirt 1938;19(1):1-2. [German].

[20] Rant Z. Exergy the new word for technical available work. Forsch Ingenieurwes 1956;22(36).

[21] Gaudreau K. Exergy analysis and resource accounting [master thesis]. Waterloo, Canada: University of Waterloo; 2009.

[22] Wall G. Exergy-a useful concept within resource accounting. Goteborg, Sweden: Institute of Theoretical Physics Goteborg; 1977.

[23] Cornelissen RL. Thermodynamics and sustainable development-the use of exergy analysis and the reduction of irreversibility. Groningen, Netherlands: Mechanical Engineering, Ph.D. Mechanical Engineering, University of Groningen; 1997.

[24] Valero A. Exergy evolution of the mineral capital on Earth. Zaragoza, Spain: Mechanical Engineering, Ph.D. Mechanical Engineering, University of Zaragoza; 2008.

[25] Szargut J. Exergy method-technical and ecological applications. Southampton, Boston: WIT Press; 2005.

[26] Fraser RA, Kay J. Establishing a role for thermal remote sensing of ecosystems: exergy analysis. In: Quattrochi D, Luvall J, editors. Thermal remote sensing in land surface processes. London (UK): Taylor \& Francis; 2003. p. $283-360$.

[27] Tsatsaronis G. Definition and nomenclature in exergy analysis and exergoeconomics. Energy 2007;32(4):249-53.

[29] Gutowski T, Branham M, Dahmus J, Jones A, Thiriez A, Sekulic D. Thermodynamic analysis of resources used in manufacturing processes. Massachusetts 
Institute of Technology [cited 2011 Apr 4]. Available from: http://web.mit. edu/2.810/www/lecture09/10-Gutowski.pdf.

[30] Tsatsaronis G. Combination of exergetic and economic analysis in energyconversion processes; Energy economics and management in industry. In: Proceedings Eur Congress. Algarve, Portugal: Tapir Academic Press; 1984 Apr 2-5. p. 151-7.

[32] Tsatsaronis G, Winhold M. Exergoeconomic analysis and evaluation of energy conversion plants. Part I-A new general methodology. Energy 1985;10:69-80.

[33] Lazzaretto A. Tsatsaronis G. SPECO: a systematic and general methodology for calculating efficiencies and costs in thermal systems. Energy 2006;31:1257-89.

[34] Jentsch A. A novel exergy-based concept of thermodynamic quality and its application to energy system evaluation and process analysis [dissertation] Berlin, Germany: Technische Universität Berlin; 2010.

[35] Petrakopoulou A. Comparative evaluation of power plants with $\mathrm{CO}_{2}$ capture: thermodynamic, economic and environmental performance [dissertation] Berlin, Germany: Technische Universität Berlin; 2011.

[36] Six articles published in topic "Energy". In: Tsatsaronis G, Cziesla F, editors. Encyclopedia of Life Support Systems (EOLSS), developed under the Auspices of UNESCO. Oxford (UK): Eolss Publishers [cited 2011 Jul 27]. Available from: http://www.eolss.net; 2004

[37] Lee KC. Classification of geothermal resources: an engineering approach. In: Proceedings of the 21st Workshop SGP-TR-151 on geothermal reservoir engineering. Stanford (CA): Stanford University, Tapir Acedemic Press; 1996. p. 85-92.

[38] Lee KC. Classification of geothermal resources by exergy. Geothermics 2001;30(4):431-42

[39] Quijano J. Exergy analysis for the Ahuachapan and Berlin geothermal fields. In: Proceedings of the world geothermal congress. Kyushu-Tohoku, Japan; Tapir Acedemic Press; 2000. p. 861-6.

[40] Baba A, Ozgener L, Hepbasli A. Environmental and exergetic aspects of geothermal energy. Energ Sourc 2006;28(7):597-609.

[41] Hepbasli A. A key review on exergetic analysis and assessment of renewable energy resources for a sustainable future. Renew Sust Energ Rev 2008;12(3): 593-661.

[42] Ozgener L, Hepbasli A, Dincer I. Energy and exergy analysis of the Gonen geothermal district heating system, Turkey. Geothermics 2005;34:632-45.

[43] Ozgener L, Hepbasli A, Dincer I. Exergy analysis of Salihli geothermal district heating system in Manisa, Turkey. Int J Energ Res 2005;29(5):398-408.

[44] Etemoglu AB, Can M. Classification of geothermal resources in Turkey by exergy analysis. Renew Sust Energ Rev, forthcoming 2006. http://dx.doi.org/ 10.1016/j.rser.2006.01.001.

[45] Ramajo H, Tritlla J, Levresse G, Tello-Hinojosa E, Ramírez G, Pérez H. New SEx tools to evaluate the evolution and anthropic disturbance in geothermal fields: the case of Los Azufres geothermal field, México. Rev Mex Cienc Geo 2010;27(3):520-9.

[46] Bodvarsson G, Eggers DE. The exergy of thermal eater. Geothermics 1972;1(3):93-5.

[47] Brook CA, Mariner RH, Makey DR, Swanson JR, Guffanti M, Muffler LJP. Hydrothermal convection systems with reservoir temperatureX90 1C. US Geological Survey Circular 790; Library of Congress Card No.:79-600006. In: Muffler LJP, editor. Assessment of geothermal resources of the United States1978 1979. p. $18-85$.

[48] Kestin J. Available work in geothermal energy. Technical report contract No.: EY-76-S-02-4051.A001.

[49] Di Pippo R, Marcille DF. Exergy analysis of geothermal power plants. Geotherm Res Counc Trans 1984;8:47-52.

[50] Di Pippo R. Second law assessment of binary plants generating power from low-temperature geothermal fluids. Geothermics 2004;33:565-86.

[51] Liebowitz HM, Mlcak HA. Design of a 2 MWKalina cycle ${ }^{\circledR}$ binary module fo installation in Húsavík, Iceland. Geotherm Res Counc Trans 1999;23:75-80.

[52] Mlcak HA. Kalina cycle ${ }^{\circledR}$ concepts for low temperature geothermal. Geotherm Res Counc Trans 2002;26:707-13.

[53] Mlcak HA, Mirolli M, Hjartarson H, Húsavíkur O, Ralph M. Notes from the north: a report on the debut year of the $2 \mathrm{MWKalina}$ cycle ${ }^{\circledR}$ geothermal power plant in Húsavík, Iceland. Geotherm Res Counc Trans 2002;26:715-8.
[54] Cerci Y. Performance evaluation of a single flash geothermal power plant in Denizli, Turkey. Energy 2003;28:27-35.

[55] Dagdas A, Ozturk R, Bekdemir S. Thermodynamic evaluation of Denizli Kızıldere geothermal power plant and its performance improvement. Energ Convers Manage 2005;46:245-56.

[56] Yildirim ED, Gokcen G. Exergy analysis and performance evaluation of Kizildere geothermal power plant, Turkey. Int J Exergy 2004;1:316-33.

[57] Ozturk HK, Atalay O, Yilan A, Hepbasli A. Energy and exergy analysis of Kizildere geothermal power plants. Turkey Energ Source A 2006;28(15):1415-24.

[58] Koreneos C, Bobolias C, Spachos T. Evaluation of utilization opportunities of geothermal energy in the Kavala region, Greece, using exergy analysis. Int J Exergy 2004;1(1):111-27.

[59] Kanoglu M. Exergy analysis of a dual-level binary geothermal power plant. Geothermics 2004;31:709-24.

[60] Setiawan B. Exergy analysis and performance evaluation of Salak geothermal power plant, Indonesia. Auckland, New Zealand: The University of Auckland, Geothermal Institute; 1996. Project Report No.: GEOTHERM 96.24.

[61] Ganjehsarabi H, Gungor A, Dincer I. Exergetic performance analysis of a "Dora II" geothermal power plant in Turkey. International Green Energy conferenceVI (IGEC-VI). Eskisehir, Turkey: Tapir Academic Press; 2011. p. 116-26.

[62] Kwambai CB. Exergy analysis of Olkaria I power plant, Kenya. In: Proceedings world geothermal congress. Bali, Indonesia; 2010.

[63] Moran HJ, Shapiro HN. Fundamental of engineering thermodynamics. 5th ed Chichester: John Wiley \& Sons; 2006.

[64] Lemmon EW, Huber ML, McLinden MO. Thermodynamic and transport properties of refrigerants and refrigerant mixture (REFPROP), NIST standard reference database 23 Ver. 8.0; 2007.

[65] Babu BV. Process plant simulation. India: Oxford University Press; 2004.

[66] Rafiqul Gani R, Hostrup M, Computer aided process design-Lecture notes [Internet]. CAPEC, Inst Kemiteknik Danmarks Tekniske Universitet Lyngby, Denmark [cited 2012 Jul 27]. Available from: http://www.capec.kt.dtu.dk/

[67] Barton PI. The equation oriented strategy for process flowsheeting [Internet]. Cambridge (MA): Department of Chemical Engineering MIT [cited 2011 Jul 27]. Available from:, http://yoric.mit.edu/oldsite/abacuss2/Lecture1.pdf; 2000.

[68] Himmelblau DM. Basic principles and calculations in chemical engineering. India: Prentice Hall; 2003.

[69] Sargent R. Verification and validation of simulation models. In: Johansson B, Jain S, Montoya-Torres J, Hugan J, Yücesan E, editors. Proceedings of the 2010 Winter Simulation conference.

[70] Köhler S, Saadat A. Thermodynamic modeling of binary cycles looking for best case scenarios, International geothermal conference. Reykjavík, Iceland; 2003 Sep.

[71] Ahrendts J. Reference states. Energy 1980;1(5):667-77.

[72] Seager TP, Theis TL. A uniform definition and quantitative basis for industrial ecology. J Clean Prod 2002;10(3):225-35.

[73] Dincer I, Kanoglu M. Refrigeration systems and applications. 2nd ed. Wiley; 2010.

[74] Dorj P. Thermoeconomic analysis of a new geothermal utilization CHP plant in Tsetserleg, Mongolia [master thesis]: University of Iceland, Department of Mechanical and Industrial Engineering; 2005. ISBN 9979-68-166-7.

[75] Holman JP. Heat transfer. McGraw-Hill Companies; 2002.

[76] Bird J. Basic engineering mathematics. 4th ed. Elsevier Science \& Technology; 2005

[77] Chen HJ, Goswami DY, Stefanakos EK. A review of thermodynamic cycles and working fluids for the conversion of low-grade heat. Renew Sust Energ Rev 2010;14:3059-67.

[78] Liu B, Chien K, Wang C. Effect of working fluids on organic Rankine cycle for waste heat recovery. Energy 2004;29:1207-17.

[79] Majcen B. Steam turbine for geothermal power plant Lunjkovec-Kutnjak [master thesis]. Zagreb, Croatia: Faculty of Mechanical engineering and Naval Architecture, University of Zagreb; 2009.

[80] Guzović Z, Majcen B, Cvetković S. Possibilities of electricity generation in the Republic of Croatia from medium-temperature geothermal sources. Appl Energ 2012;98:404-14. 